Two-dimensional fictitious truss method for estimation of out-of-plane strength of masonry walls

Muhammad Ridwan, M.D; Isamu Yoshitake; Ayman Y Nassif

Abstract: The truss method is rarely used to analyze a masonry wall, especially a masonry wall under a load in the out-of-plane direction. The present study proposes a model called the fictitious truss method (FTM) to determine the ability of masonry structures to withstand a lateral load within their elastic deformation capacities, and introduces a two-dimensional linear static model for masonry walls. The model represents the effect of flexural interaction by computing the stress and strain in the axial direction of the material and by considering uniaxial force effects on masonry elements. Pressure is applied to the surface area of the wall sequentially to predict the ultimate tension and compression cracking. FTM modeling is validated using previously obtained results for confined and unconfined masonry walls and for reinforced and unreinforced masonry walls. The FTM is a reliable method of assessing the out-of-plane strength of masonry structures owing to its conceptual accuracy, simplicity, and computational efficiency.

Keywords: fictitious truss method, masonry structure, out-of-plane strength. 


\title{
Two-dimensional fictitious truss method for estimation of out-of-plane strength of masonry walls
}

\author{
Muhammad Ridwan $^{1}$, Isamu Yoshitake ${ }^{2}$ and Ayman Y. Nassif ${ }^{3}$ \\ ${ }^{1}$ Department of Civil Engineering, Padang Institute of Technology, \\ Jalan Gajah Mada Kandis Nanggalo Padang, Indonesia, e-mail: mhd.rid.wan.itp@gmail.com \\ (Ph.D. Candidate of Yamaguchi University) (Corresponding author) \\ ${ }^{2}$ Department of Civil and Environmental Engineering, Yamaguchi University, \\ Tokiwadai 2-16-1, Ube, Yamaguchi, 755-8611, Japan, e-mail: yositake@ yamaguchi-u.ac.jp \\ ${ }^{3}$ School of Civil Engineering and Surveying, University of Portsmouth, Portsmouth PO1 3AH, \\ United Kingdom, e-mail: ayman.nassif@port.ac.uk
}




\section{Abstract}

2 The truss method is rarely used to analyze a masonry wall, especially a masonry wall under a

3 load in the out-of-plane direction. The present study proposes a model called the fictitious truss

4 method (FTM) to determine the ability of masonry structures to withstand a lateral load within

5 their elastic deformation capacities, and introduces a two-dimensional linear static model for

6 masonry walls. The model represents the effect of flexural interaction by computing the stress

7 and strain in the axial direction of the material and by considering uniaxial force effects on

8 masonry elements. Pressure is applied to the surface area of the wall sequentially to predict the

9 ultimate tension and compression cracking. FTM modeling is validated using previously

10 obtained results for confined and unconfined masonry walls and for reinforced and unreinforced

11 masonry walls. The FTM is a reliable method of assessing the out-of-plane strength of masonry

12 structures owing to its conceptual accuracy, simplicity, and computational efficiency.

14 Keywords: fictitious truss method, masonry structure, out-of-plane strength. 


\section{Introduction}

The masonry wall is widely used for its low cost in low-rise construction in various countries. Additionally, a ring beam around a masonry structure (confined masonry) wall is recommended for the prevention of injuries and casualties that might occur in the unexpected collapse of a masonry wall. One form of masonry wall collapse is due to loading in the out-ofplane direction, which can occur, for example, in an earthquake or a flood. However, there is no indication that many masonry walls have collapsed under wind pressure after the completion of their construction [4], which can be considered evidence of the adequacy of their construction.

There is a connection between walls and reinforced concrete, given the different deformations of the two materials in response to loading. This is strongly dependent on the type of masonry used for infill. Masonry can be built using different kinds of units (e.g., solid or hollow), unit materials (e.g., clay or concrete), and mortar, depending on the region. The infill wall and the confinement are usually connected with mortar (unreinforced masonry) using an anchor and reinforcement (reinforced masonry).

Research on out-of-plane loading has included experiments and theoretical analysis using different analytical methods, but there has been far less research on out-of-plane loading of masonry walls than on in-plane loading of masonry walls. Some experimental studies have been performed on out-of-plane behavior of masonry reinforced walls [1-3], unreinforced masonry walls $[4,5]$, infill masonry walls [6-8] and confined masonry walls [9-11]. Based on these studies the main variables that affect the out-of-plane behavior of masonry walls are the aspect ratio (height divided by length), wall support conditions, wall slenderness ratio (height divided by thickness), axial load, in-plane stiffness of surrounding elements, wall openings, and unit 
type. Moreover, the out-of-plane behavior of confined walls is different than that observed for

39 unreinforced, reinforced, and infill walls. The difference is mainly associated with construction

40 procedures and wall reinforcement details. The differences between infill and confined walls are

41 as follows. Firstly, confined walls consist of unreinforced panels surrounded by flexible

42 reinforced concrete confining elements. The wall panels are constructed first, and later the

43 confining elements are constructed. Infill walls consist of unreinforced or reinforced masonry

44 walls surrounded by stiff concrete or structural steel frames [12]. The frames are constructed

45 first, and later the masonry panels are constructed. This type of construction causes gaps between

46 the frames and the masonry panels. Construction gaps delay the formation of arching action [6,

47 13].

The aspect ratio and slenderness ratio $[4,10,12,14]$ have been shown to affect the strength

49 of unreinforced masonry (URM). Some researchers have used finite element (FE) theory and

50 software to analyze masonry walls under out-of-plane loading. Drysdale et al. [4] used FE elastic

51 plate analysis, Noor-E-Khuda et al. [1] used the explicit FE method and a layered shell model,

52 and La-Mendola et al. [15] and Milani et al. [16] used commercial FE software. The FE method

53 is very helpful, but it is complex and requires considerable cost.

On the other hand, numerical modeling of the out-of-plane response of infill frames was

55 reviewed by Asteris et al. [17], whose in-depth literature review included some models of out-of-

56 plane responses for infill frames. There are flexural-action-based models and arching-action-

57 based models.

Cavalery et al. [18] investigated modeling of the out-of-plane behavior of masonry walls.

59 They proposed analytical modeling of the moment curvature law and a numerical procedure to 60 determine the flexural response of masonry cross sections, including nonlinearity owing to the 
$61 \sigma-\varepsilon$ law in compression and the assumption of limit-tension material. This investigation

62 simplifies the solution to a problem in which the bending moment increases because of increases

63 in the eccentricity of the constant compressive axial load. This investigation used previous

64 calcarenite and clay brick wall experimental data to validate the analytical model of the moment-

65 curvature curve. This approach can be used for various classes of materials and structures, and is

66 easy to apply means of the analytical moment-curvature law, allowing a fitted "exact" numerical

67 result to be defined. In this investigation, the tensile strength was negligible."

68 Some researchers have also investigated near-surface-mount-reinforced masonry walls. [15, 19-

69 22]. They used fiber-reinforced polymer (FRP), carbon-fiber-reinforced polymer (CFRP) strips,

70 and polymer-textile-reinforced mortar to reinforce a masonry wall. These materials are used to

71 improve the out-of-plane performance of a URM wall. Near-surface-mount-reinforced masonry

72 walls are very helpful in increasing the strength of masonry but are strongly affected by the type

73 of reinforcement used.

URM panels in reinforced concrete frames were investigated by Tu et al. [8] and Furtado

75 et al. [23]. Tu et al. investigated the out-of-plane behavior of URM walls in shaking table tests.

76 They used an analytical model for analysis. Furtado et al. evaluated the combination of in-plane

77 and out-of-plane behaviors by comparing two infill masonry walls subjected to monotonic out-

78 of-plane loading and cyclic out-of-plane loading.

Many theories have been proposed to investigate the strength and behavior of masonry

80 structures in the out-of-plane direction, as shown in Table 1. However, these theories are based

81 on and limited to certain experimental configurations. Most studies on the out-of-plane behavior

82 of masonry walls have been experimental works and thus time-consuming and expensive [1]. It

83 has been concluded that the method that most accurately predicts the out-of-plane strength of 
84 confined walls is the bidirectional strut method. This method is an iterative procedure based on 85 two-way arching action.

The truss model is rarely used in calculations for a masonry wall structures, but several

87 truss models have been extensively used for analysis of the nonlinear behavior of masonry

88 infills. A truss model for masonry structures was proposed by Lu et al. [24] in research on a

89 nonplanar reinforced concrete wall. Recently, Moharrami et al. [25] used the truss model for the

90 analysis of masonry structures employing nonlinear truss modeling, which was used in the

91 analysis of shear failure in the in-plane direction of the wall.

The present study proposes a new method of using a truss as a structural element of a

93 masonry wall in order to analyze the out-of-plane strength of a masonry structure. The aim of

94 present study is a model oriented to the determination of out of-plane resistance. The proposed

95 fictitious truss method (FTM) provides practitioners and academics with analytical results and 96 can be modified for a variety of masonry walls.

\section{2. Material and Methods}

The FTM creates patterns of stress distribution in a flexural element structure. The 99 geometry of the FTM is obtained by centralizing and simplifying the force acting on a wall. The 100 elements establish truss blocks and then configure the truss structure as indicated in Fig. 1.

\subsection{Determination of truss geometry}

102 A truss model requires cross-sectional dimensions and determination of the geometry of truss

103 elements as well as applicable material models. The first step is establishing the dimensions of 104 the truss and of the truss elements considering the real dimensions of the masonry structure. In 
105 the cross section of the masonry structure, $t$ is the thickness of the masonry and is not directly 106 used in the FTM models.

The FTM makes the following assumptions. The thickness of the masonry wall is the 108 initial height of the truss model $(t)$. The effective cross section of the truss element is a square 109 shape ( $a \times b_{\text {eff. }}$ ), the cross section is the effective area of compression stress in a flexural beam, 110 the aspect ratio is less than one (i.e., $\mathrm{H} / \mathrm{L}<1$ ), and the truss is fictitious. The truss can be 111 calculated as a numerical value until early fracture, and buckling can be ignored. If 112 reinforcement is used, its arrangement must be regular.

113 The shape of the truss model is shown in Fig. 2. There are three types of shapes: $v_{t}$ is a 114 vertical truss, $h_{t}$ is a horizontal truss, and $d_{t}$ is a diagonal truss. A diagonal truss can be a single 115 diagonal or double diagonal truss.

The truss geometry defines the geometry of the vertical cross section of the brick and 117 determines the height of the masonry wall. Each block truss is the representative geometry of the 118 brick and mortar. The height of the truss $\left(v_{t}\right)$ is the effective width of a cross section of the 119 masonry wall $\left(t_{\text {eff }}\right)$, while the width $\left(h_{t}\right)$ of the truss is the effective thickness of the mortar or unit 120 masonry. $b_{\text {eff }}$ is the assumed width of the unit load to be used. It is obtained from the length of 121 the brick unit. $t_{\text {eff }}$ is the effective height of a cross section of the truss model. It is obtained from 122 the equivalent inertia of the effective cross section as shown in Fig. 3 and by solving equation (1) 123 below:

$$
I_{t o t}=I_{e q}
$$

125 where $I_{\text {tot }}=\frac{1}{12} b_{e f f} t^{3}$ and $I_{e q}$ is the inertia unit equivalent of the masonry element which can be 126 solved with the provision that $A_{l}=A_{2}$ and the equation

$$
I_{e q}=\sum_{1}^{n} I_{n}+\sum_{1}^{n}\left(A_{n} y_{n}^{2}\right)
$$


$128 y$ is thus obtained if $\mathrm{n}=2$ as

129

$$
y=\sqrt{\frac{I_{t o t}-2 I_{n}}{2 A_{n}}}
$$

The result is that $t_{e f f}$ is $2 y$

The total height of the vertical truss elements is $t_{w}=2 y+a$; however, the height used in height of a truss element that has parameters for the equivalent stress of the block parameter.

The total stress area in compression is $A_{c}=a b_{\text {eff. }}$ In accordance with SNI 03-2847-2013

135 [31], the depth of the equivalent stress block $(a)$ is obtained as $a=\beta_{l} c$, where $c$ is the distance 136 from the center of mass to the top and $\beta_{1}=0.85 . \beta_{1}$ is a function of the strength class of 137 materials: $\beta_{1}=0.85$ for $f^{\prime}{ }_{m e}<30 \mathrm{MPa}$, and is reduced by 0.008 for every increase of $1 \mathrm{MPa}$ in 138 compressive strength; it should not be less than 0.65 . Therefore, $a=0.85 c$ and $\alpha=1$ for actual 139 compressive strength, and 0.85 for the compressive strength equivalent. $b_{\text {eff }}$ is the length of the 140 brick or the length of the effective area of pressure used as the effective width. $A_{c}=A_{t}=a b_{\text {eff }}$ is 141 used for a masonry wall without reinforcement and $A_{t}=A_{r}$ is used for a masonry wall with 142 reinforcement, where $A_{t}$ is the area of tension, $A_{c}$ is the area of compression, and $A_{r}$ is the area of reinforcement. Typical cross-sectional dimensions used in the FTM are shown in Fig. 1.

144 The geometric dimension of the mortar part is the same for the brick and unit parts. The material 145 parameters should be set according to the properties of each material, and the material modeling 146 assumption in tension and compression is isotropic, linear, elastic material. An elastic material 147 may show linear or nonlinear behavior. In this study, we assume linear behavior. For linear 148 elastic materials, stresses are linearly proportional to strains $(\sigma=E \varepsilon)$ as described by Hooke's 
149 law. The law is applicable for material properties that are independent of coordinates 150 (homogeneous) and material properties that are independent of the rotation of the axes at any

151 point in a body or structure (isotropic materials). Here only two elastic constants (modulus of 152 elasticity E and Poisson's ratio v) are needed for linear elastic materials.

The FTM can be used to determine the strength of a confined or unconfined masonry 154 structure in the out-of-plane direction.

\subsection{Schematic of the FTM}

156 The FTM determines the out-of-plane strength of a masonry wall structure and involves the 157 following steps:

158 - Check that the aspect ratio $(\mathrm{H} / \mathrm{L})$ of the masonry structure is less than 1.0.

159 - Provide material properties including the elasticity, specific gravity, Poisson's ratio, 160 compressive strength, tensile strength, and others.

161 - Determine the widely assumed pressure area $\left(b_{\text {eff }}\right)$.

162 - Determine the effective height of the element truss $\left(a=\beta_{1} c\right)$.

163 - Arrange $A_{c}=A_{\mathrm{t}}=a b_{\text {eff }}$ to obtain $y($ Eqs. 1, 2, 3).

164 - Determine the effective thickness of the truss structure $t_{\text {eff }}=2 y$.

165 - Obtain the model and its dimensions by determining the boundary conditions of the 166 masonry structure.

167 - Analyze the FTM structure to obtain the element truss force.

$168 \quad-\quad$ Apply the load $\left(P_{e q}\right)$ gradually until there is cracking in areas of tension and compression. 169 All loads are applied as concentrated equivalent loads acting on the truss joints. The FTM is 170 schematically shown in Fig. 5. 
171 The FTM may not be applicable physically, but it can be performed numerically. The element

172 truss force can be analyzed using classical mechanics methods, other methods typically used to

173 calculate truss structures, or using FE software. After determining the truss element and truss

174 structure, the loading can be applied gradually while checking the strain in compression and the 175 tension truss element condition.

\section{$177 \quad 2.3$ Material models}

178 The stress-strain relationship of truss elements representing masonry walls is shown in Fig. 6.

179 The tensile strength and compressive strength of the mortar and the units are interconnected. In

180 the present study, the vertical and horizontal truss elements are the studied variables while the 181 diagonal truss element distributes forces to the vertical and horizontal truss elements.

182 The material model of masonry is linear and elastic for brittle material; likewise for units and 183 mortar. The failure criterion of the FTM model is the maximum principal strain by uniaxial 184 loading on a truss member. The Hooke's law concept $\varepsilon=\frac{\sigma}{E}$ can be applied to predict when 185 either of the principal strains resulting from the principal stresses $\left(\sigma_{1,2}\right)$ meets or exceeds the 186 maximum strain corresponding to the yield strength $\left(\sigma_{y}\right)$ of the material in uniaxial tension or 187 compression.

The FTM requires the force acting on a truss element to be in the critical region of the 189 mid-span of the truss structure, where there is tension and compression on either side. Tension 190 and compression may occur in mortar and brick in structural elements. It is therefore necessary 191 to choose either brick or mortar as the material when determining the strength of masonry 192 structures. 
Almeida et al. [26] investigated hollow bricks and the brick-mortar interfaces under uniaxial tension for hollow bricks sourced from Portugal and Spain. Testing various brick types revealed a similar uniaxial response in tension and compression (Fig. 6). Figure 6a shows the relationship between tension stress and strain. Stress increases linearly to a peak value before gradually and nonlinearly decreasing. The present paper focuses only on the behavior until the peak tensile load is reached. The same behavior is seen for both raw materials and materials such as FRP, CFRP, and steel. Almeida et al. [26] found that elongation values for hollow brick obtained with different peak tensile loads ranged from 3 to $10 \mu$ while those for mortar were less than $5 \mu$. The tensile stress values ranged over $2.75-3.82$ and $1.93-2.25 \mathrm{~N} / \mathrm{mm}^{2}$, respectively, for the hollow brick and mortar. In the present study, the tensile stress was assumed to be 3 and $2 \mathrm{~N} / \mathrm{mm}^{2}$, respectively, for the hollow brick and mortar, and the tensile strain was assumed to be 0.001 . Figure $6 \mathbf{b}$ shows the relationship between compression stress and strain.

Kaushik et al. [27] found cracking at strain values from 0.0023 to 0.00375 . Based on these data, the present study used 0.003 as the cracking point for masonry elements. Kaushik et al. stated that the values of $E_{b}, E_{j}$, and $E_{m}$ for masonry walls are approximately

$$
\begin{aligned}
& E_{b} \approx 300 f_{b}, \\
& E_{j} \approx 200 f_{j}, \\
& E_{m}=550 f^{\prime}{ }_{m} .
\end{aligned}
$$

Corresponding coefficients of variance were $0.35,0.32$, and 0.3 respectively. These results are in line with the basic formula used by Eurocode 6 [28] regarding the characteristic compressive strength of masonry. Following the above research, $E_{b}, E_{j}$, and $E_{m}$ for masonry can be used in the present study; however, the present study considers the elastic linear range. 


\subsection{Aspect ratio, slenderness ratio, and weight reduction}

217 A masonry structure comprising multiple walls subjected to out-of-plane loading has an aspect 218 ratio $(A R)$. The present study does not consider $A R \geq 1$ except for the case of the one-way 219 vertical wall (with a plane of failure parallel to the bed joints). This is because several previous 220 studies [14] revealed that structural rigidity is higher in the horizontal direction than in the 221 vertical direction if $A R \geq 1$. However, the approach of using $P=(0.3 A R+0.7) P$ can be invoked 222 for $\mathrm{AR}>1$.

The slenderness ratio also affects the masonry structure. The thickness of a masonry wall ( $t$ ) affects the stiffness and strength of the wall. In the present study, $t$ is a variable that has been resolved in various stages used in determining the stiffness and strength of a masonry wall. The stages seek the equivalent thickness of the wall $\left(t_{\text {eff }}\right)$, which represents the truss. automatically. A solid element is used as the truss element. Therefore, the specific gravity of the truss must be adapted to the specific gravity of the solid masonry elements. This can be achieved by multiplying the specific gravity by a factor $\xi$ for masonry elements:

$$
\gamma_{e q(u)}=\xi \gamma_{u}
$$

$$
\gamma_{e q(m)}=\xi \gamma_{m}
$$

233 where $\xi=\frac{b_{e f f} t}{2 a\left(\frac{t_{e f f}}{\sin \theta}+t_{e f f}+b_{e f f}\right)}, \gamma_{e q}$ is the specific gravity equivalent of a unit or of mortar, $\xi$ is the 234 specific gravity factor, $\gamma_{u}$ is the specific gravity of the unit, and $\gamma_{m}$ is the specific gravity of the 235 mortar. Geometrically, the self-weight of a truss element affects the behavior of masonry 236 structures. The load given to the structure is therefore an additional external load. For instance, if 237 the thickness of the wall is $(t)=120 \mathrm{~mm}$, the width of the unit load to be used is $\left(b_{e f f}\right)=210 \mathrm{~mm}$, the 
238 depth of the equivalent stress block is $(a)=51 \mathrm{~mm}$, and the effective width of a cross section of the

239 truss model is $\left(t_{e f f}\right)=69.13 \mathrm{~mm}$, then the value of the specific gravity factor $(\xi)$ is 0.655 . This value

240 has a significant influence on the self-weight of a masonry structure.

241 3. Results

242 The FTM was validated using the results of analysis of out-of-plane masonry structures

243 conducted in previous studies. Truss analysis can be performed by using matrix methods as for a

244 two-dimensional truss using the direct stiffness method. In this study, this is performed using

245 SAP2000 software [31]. The basic data are entered in accordance with the constitutive modeling

246 approach. Both truss shapes were used and validated for masonry wall structures subject to out-

247 of-plane loading. Material properties from the literature were used as input data in analyzing the

$248 \quad$ FTM structure with FE software.

\section{$250 \quad 3.1$ Validation 1}

251 The first validation of the FTM was conducted for a model used by Varela-Rivera et al. [9], 252 namely six confined masonry walls with reinforced concrete. The specifications of the materials

253 and dimensions of the walls are given in Table 2. Each wall was comprised of hollow blocks in a

254 half-running bond pattern. The dimensions of the concrete confining elements were $0.15 \times 0.2 \mathrm{~m}$

$255 \times 0.4 \mathrm{~m}$ for E-1, E-2, E-4, and E-5, and $0.12 \mathrm{~m} \times 0.2 \mathrm{~m} \times 0.4 \mathrm{~m}$ for E-3 and E-6. Each wall was

256 confined by reinforced concrete around its perimeter. A load was applied to the masonry wall 257 using air bags with dimensions of $1.2 \mathrm{~m} \times 3 \mathrm{~m}$ (Fig. 7).

258 The air bags were filled gradually until the ultimate cracking of the masonry walls. The thickness 259 of mortar connecting the blocks of masonry units was $10 \mathrm{~mm}$. 
The results of this numerical experiment $\left(W_{e}\right)$ were compared with those obtained by

261 Varela et al. $[10,11]$ using the spring-strut method $\left(W_{s s}\right)$, and were previously compared with

262 the results of previous studies conducted by Varela-Rivera et al. [9] using the yield-line method

$263\left(W_{y l}\right)$, failure-line method $\left(W_{f l}\right)$, and compressive strut method $\left(W_{c s}\right)$. The yield-line method $\left(W_{y l}\right)$

264 is theoretically not recommended for brittle materials such as masonry, but is still used to predict

265 the out-of-plane strength of walls [4]. The failure-line method $\left(W_{f l}\right)$ is a modification of the yield

266 line method based on the idea that, prior to the formation of the final failure cracking pattern,

267 some cracks are already formed, and their contribution to the internal work should not be

268 included. For this reason, the failure line method predicts lower strength than the yield line

269 method. The compressive strut method $\left(W_{c s}\right)$ was proposed by Abrams et al. [6] for infill walls

270 surrounded by concrete frames. In Abrams' work, an infill wall was subjected to uniform

271 pressures. It was assumed that, after the formation of a given cracking pattern, a wall was

272 divided into segments.

273 The structure and description of the walls and the FTM model proposed here are presented in

274 Fig. 8. Results of FTM analysis are denoted by $W_{t}$ and $W_{c}$. FTM results are presented and

275 incorporated in Fig. 9.

276 The example calculations of $b_{\text {eff }}$ and $t_{\text {eff }}$ are as follows:

277

278

279

280

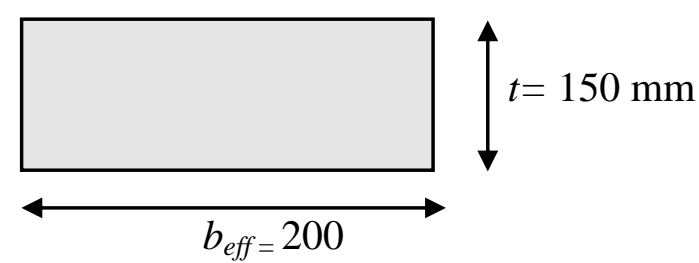

$I_{\text {tot }}=\frac{1}{12} b_{e f f} t^{2}=56,250,000 \mathrm{~mm}^{4}$

$$
c=0.5 t, \beta=0.85 \rightarrow a=\mathrm{c} \beta=75 \times 0.85=63.75 \mathrm{~mm}
$$

282

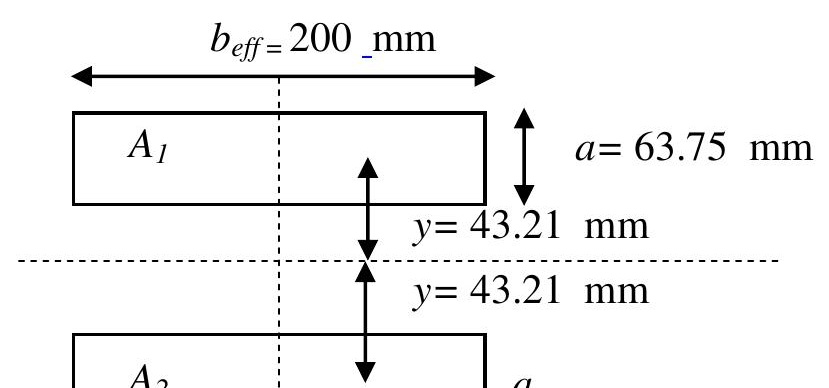




$$
\begin{gathered}
I_{e q}=\sum I_{n}+\sum A_{n} y^{2} \\
I_{e q}=56,250,000=I_{t o t}
\end{gathered}
$$

\begin{tabular}{|c|c|c|c|c|}
\hline$n$ & $I_{n}=1 / 12 b_{e f f} \cdot a^{3}\left(\mathrm{~mm}^{4}\right)$ & $A_{n}=b_{e f f} \cdot a\left(\mathrm{~mm}^{2}\right)$ & $y^{2}$ & $\left(\mathrm{~mm}^{4}\right)$ \\
\hline 1 & $4,318,066.406$ & 12,750 & $1,867.21$ & $28,125,000$ \\
\hline 2 & $4,318,066.406$ & 12,750 & $1,867.21$ & $28,125,000$ \\
\hline & $8,636,132.813$ & & $I_{e q}=$ & $56,250,000$ \\
\hline
\end{tabular}

291 Equation 3:

$$
y=\sqrt{\frac{I_{t o t}-2 I_{n}}{2 A_{n}}}=43.21 \mathrm{~mm}
$$

The result is that $\mathrm{y}=43.21 \mathrm{~mm}$; hereafter, $t_{\text {eff }}=2 y=86.42 \mathrm{~mm}$ and $t_{w}=150.17 \mathrm{~mm}$.

FTM results are explained further in the Discussion section.

\subsection{Validation 2}

297 The second validation of the FTM was conducted for a model used by Hamoush et al. [29], who 298 investigated the behavior of a surface-reinforced masonry wall under out-of-plane loading. The 299 wall was reinforced with FRP and had dimensions of $900 \mathrm{~mm} \times 600 \mathrm{~mm} \times 200 \mathrm{~mm}$. There were 30018 specimens in total. Specimens had a single or double layer of FRP and a distance from the 301 fiber to the support of $0, d / 2$, or $d / 4$, where $d$ is the span from the support to the first of point load 302 on the masonry wall specimen. Specimens were constructed with hollow bricks made from 
mortar with a thickness of $25 \mathrm{~mm}$. A single hollow block unit had two holes. The dimensions of

304 a hollow block were $400 \mathrm{~mm} \times 200 \mathrm{~mm} \times 200 \mathrm{~mm}$. The thickness of the HB was the effective

305 compressed zone in this validation. The web fiber used in the validation was constructed with

306 Tyfo Hi-Clear epoxy resin with an ultimate tensile strength of $414 \mathrm{MPa}$, ultimate elongation of

$3072.0 \%$, elastic modulus of $27,580 \mathrm{MPa}$, and design thickness of $0.4 \mathrm{~mm}$ per layer. The Hamoush

308 test setup and FTM model are shown in Fig. 10.

309 The height $\left(t_{e f f}\right)$ of the truss was the center distance between the top and bottom of the hollow 310 block.

311 Several methods can be used to analyze the FTM, such as the consistent deformation

312 method, matrix method, finite element method, or FE software. Here, we analyzed the FTM 313 structure using FE software using material properties taken from the literature as input data. The 314 results of this validation are presented in Fig. 11. The FTM results compared with the three 315 experimental specimen results are explained in the Discussion section.

\section{$317 \quad 3.4$ Validation 3}

The third validation of the FTM was conducted for low-quality brick considered by Anil et al. [21]. The brick had a strength of $2.5 \mathrm{MPa}$, hollow ratio of $65 \%$, and dimensions of $185 \mathrm{~mm}$ $320 \times 185 \mathrm{~mm} \times 135 \mathrm{~mm}$. The mortar was of higher strength $(5.2-7.1 \mathrm{MPa})$. The dimensions of the 321 masonry walls were $1,600 \mathrm{~mm} \times 1,100 \mathrm{~mm} \times 135 \mathrm{~mm}$. CFRP was coated on the side adjacent to 322 the load side to retrofit the walls. The properties of the CFRP are given in Table 3. The test setup 323 is presented in Fig. 12.

The CFRP was used in diverse arrays with different anchor arrangements and different 325 combinations of vertical, horizontal, and diagonal arrangements. The CFRP arrangements were 
applied to 11 samples. Five sample results obtained using the FTM in this validation were satisfactory, as presented in Fig. 13. The results are close to the experimental values.

\section{Discussion}

The use of FTM to analyze a confined masonry wall under out-of-plane loading was convincing in the first validation. The maximum pressure generated by the FTM (i.e., the strength of the wall) is given in Fig. 9. $W_{t}$ and $W_{c}$ are the pressures required to produce forces on the tension truss and compression truss, respectively, that cause the wall to fail. Experimental results obtained by Varela-Rivera et al. [9] and displayed in Fig. 9 revealed that specimens with similar aspect and slenderness ratios (E-1 and E-2; E-4 and E-5) have a lower out-of-plane strength than specimens with lower in-plane stiffness (E-1 and E-4). In the case of specimens with similar aspect ratios and in-plane stiffness (E-2 and E-3; E-5 and E-6), $W_{e}$ is greater for specimens with smaller slenderness ratios (E-2 and E-5). The difference is related to the greater axial compressive strength of the block. The same behavior is seen in the above results obtained using the FTM. In contrast, the yield-line method and failure-line method underestimate $W_{e}$.

The FTM provides the strength resulting from a compression crack $W_{c}$ and the strength resulting from a tension crack $W_{t} . W_{c}$ represents the value of the strength resulting from an experimental crack $W_{e}\left(\mathrm{E}-2, \mathrm{E}-3, \mathrm{E}-4\right.$ and E-5); $W_{e}$ is similar to $W_{c}$. The strength of masonry using $W_{c s}$ (the compressive strut method) and $W_{s s}$ (the spring-strut-method) overestimated $W_{e}$; this comparison is similar to that for $W_{t}$ and $W_{c}$ obtained in FTM analysis. These results are consistent with the effects of the slenderness ratio of a masonry structure in that the thickness of the masonry structure affects the pressure needed for the structure to fail. $W_{t}$ and $W_{c}$ were slightly greater than $W_{y l}$ and $W_{e}$. 
The FTM provided a value close to the experimental result $\left(W_{e}\right)$ and the result of the spring-strut method $\left(W_{s s}\right)$. However, $W_{c}$ was a greater than $W_{e}$ while $W_{t}$ was lower than $W_{e}$ for specimen E-1 owing to the difference in the rigidity of confinement. The rigidity of confinement depends on the reinforcement factor; this will be considered in the next FTM study. $W_{t}$ appears almost identical to $W_{y l}$ and $W_{f l}$. This indicates that the previous method of obtaining $W_{y l}$ and $W_{f l}$ can only be used at one stage of cracking. The previous method can be applied only to a confined masonry wall. The above comparison reveals that FTM is useful in analyzing the strength of confined masonry walls.

The percentage of error (PoE) comparison between FTM and experimental and analysis results can be seen in Table 5. It is shown that for $W_{e}(\mathrm{E}-1)$ relative to FTM $\left(W_{t}\right)$, PoE values are 3.912.1\%; for E-2, E-4, and E-5 relative to $W_{c}$, PoE values are 1.9-20.9\%; for $W_{y l}$ relative to $W_{t}$, PoE values are $0.7-21.8 \%$; for $W_{f l}\left(\mathrm{E}-2, \mathrm{E}-4, \mathrm{E}-5\right.$ end E-6) relative to $W_{t}$, the PoE values are 1.2$14.2 \%$; for $W_{s s}\left(\mathrm{E}-4\right.$ and E-6) relative to $W_{c}$, PoE values are $3.3 \%, 7.4 \%$, and $28.6 \%$, and only $W_{c s}$ relative to $W_{t}$ or $W_{c}$ have PoE values greater than $30 \%$." From these results it is seen that the first crack of a masonry structure can be caused by tensile stress or compressive stress.

In the second validation, FRP was used to provide tension on the truss element. Results obtained with FTM show that the addition of FRP strengthens masonry structures, which is in line with the results of experiments. The FRP would fail before cracking appears in the area of compression [29]. The FTM reveals that the tensile load does not reach a maximum and that there is cracking as a result of compressive strain.

Figure 11 and Table 6 shows that cracking, as a result of the truss tension obtained with the FTM, is similar to the experimental result. The percentage of error in this validation for all comparisons was between 0.82 and $27.01 \%$. 
The addition of the FRP layer provides a peak load before cracking that is higher than

372 that for a single layer along with an increase in the loading capacity. Similarly, the two layers

373 reduce the deformation of the structure. Apparently, retrofitting using a single layer and

374 retrofitting using a double layer are similar under tension of the truss element, but the double

375 layer provides different compressive strengths for the compression of the truss element. A double

376 layer of FRP increases structural integrity, especially when the FRP layers extend to the supports

377 [29]. Various installations of a single layer of FRP strengthen the system only slightly.

Figure 13 and Table 7 compare the results obtained using FTM with the experimental 379 and analytical results of Anil et al. [21] in the third validation experiment. The FTM was used in 380 cases with and without CFRP.

The diagonal modeling of CFRP in this validation is not applicable because the diagonal 382 combination of CFRP strips is not handled in the two-dimensional FTM; it could be applied in 383 three-dimensional FTM. Therefore, only certain reinforcements are used in this case, namely the 384 reinforcements of samples $1,8,9,10$, and 11 .

385 Sample 1 did not use CFRP and cracked at low load in sample 10. FTM values overestimated the 386 load capacities compared with experimental values. For sample numbers 8, 9, and 11, FTM 387 underestimated the load capacity results found by analysis. The average overestimation of 388 samples 1 and 10 were around 4.27\% (FTMDD) and 13.98\% (FTMSD) of the load capacity 389 values, and the average underestimation of samples 8, 9, and 11 were between $0.07 \%$ (FTMSD) 390 and $13 . .98 \%$ (FTMSD) of the load capacity values. The load capacity then increased as CFRP 391 was applied and the truss element was compressed. FTM provided results similar to the 392 experimental results, although there were slight differences owing to the modeling of the anchor 
393 in the FTM models. The analysis of Anil et al. [21] overestimated the results obtained using 394 FTM and the results obtained in experiments. Anil et al. did not record an analysis of sample 1.

\section{5. Conclusions}

396 FTM was applied to a wide variety of planar masonry structures, both confined and unconfined 397 as well as both with and without reinforcement. The structures corresponded to a simple beam, 398 cantilever, distributed load, and concentrated load. The following conclusions are drawn from 399 the results of validation tests on FTM.

400 - FTM can be applied to various conditions of masonry structure models subject to out-of-plane 401 loading. Specifically, FTM can be applied to a structure having an aspect ratio less than 1.

402 - FTM produces satisfactory results if the reinforcement of the masonry structure is uniform in 403 direction and runs parallel to the span of the structure. However, diagonal reinforcement is 404 difficult to model using FTM.

405 - FTM overcomes problems faced by previous methods because it reproduces compression and 406 tension failures.

407 FTM is expected to serve as a tool for evaluating the strength of a masonry wall under out-of408 plane loading. The FTM's effectiveness in three-dimensional modeling of walls will be 409 investigated further in future work. The FTM will thus be of use to both academics and 410 practitioners. 


\section{The symbol list}

\begin{tabular}{|c|c|c|c|}
\hline$A_{n}$ & effective area $n$ of element truss & $I_{\text {tot }}$ & inertia unit of masonry element \\
\hline$A_{c}$ & pressure effective area & $\theta_{d}$ & angle of diagonal truss \\
\hline$A_{r}$ & reinforcement effective area & $\sigma u$ & ultimate stress \\
\hline$A R$ & aspect ratio & $L$ & length of masonry wall \\
\hline$A_{t}$ & tension effective area & $n$ & total number of data points \\
\hline$a$ & depth of the equivalent stress block & $P$ & joint load \\
\hline$\alpha$ & constants representing contribution of & $p$ & joint load \\
\hline$\alpha$ & $\begin{array}{l}\text { bricks compressive strengths on } f_{m} \\
\text { shape factor of compressive area }\end{array}$ & $\begin{array}{l}P_{e q} \\
P o E\end{array}$ & $\begin{array}{l}\text { joint load equivalent } \\
\text { percentage of error }\end{array}$ \\
\hline$b_{\text {eff }}$ & width of unit load to be used & $Q$ & uniform load \\
\hline$\beta$, & $\begin{array}{l}\text { constants representing contribution of } \\
\text { mortar compressive strengths on } f_{m}\end{array}$ & $t_{e f f}$ & $\begin{array}{l}\text { effective width of a cross section of truss } \\
\text { model }\end{array}$ \\
\hline$\beta_{1}$ & function of strength class of materials & $v_{t}$ & vertical truss \\
\hline$c$ & distance from center of thickness of & $t$ & thickness of masonry \\
\hline$d_{t}$ & $\begin{array}{l}\text { masonry wall to the top } \\
\text { diagonal truss element }\end{array}$ & $t_{w}$ & thickness of masonry \\
\hline$u_{t}$ & displacement & $\gamma_{e q(u)}$ & specific gravity equivalent of unit \\
\hline$E$ & Young's modulus & $\gamma_{e q(m)}$ & specific gravity equivalent of mortar \\
\hline$E_{b}$ & modulus of elasticity of bricks & $\xi$ & specific gravity factor \\
\hline$E_{m}$ & modulus of elasticity of masonry & $\gamma_{u}$ & specific gravity factor unit \\
\hline$E_{j}$ & modulus of elasticity of mortar & $\gamma_{m}$ & specific gravity factor mortar \\
\hline$\varepsilon^{\prime}{ }_{m}$ & peak strain in masonry, i.e., compressive & $\gamma_{e q}$ & specific gravity equivalent \\
\hline & strain corresponding to $f m_{-}$ & $t_{w}$ & total height of vertical truss elements \\
\hline$\varepsilon_{m}$ & ressive strain in masonry & $v_{t}$ & vertical truss element \\
\hline$\varepsilon$ & strain & $W_{e}$ & strength of masonry by using \\
\hline$E_{c}$ & modulus of elasticity of concrete & & experimental method \\
\hline$f_{j}$ & compressive strength of mortar & $W_{s s}$ & strength of masonry by using spring-strut \\
\hline $\begin{array}{l}f_{m}^{\prime} \\
f_{m}\end{array}$ & $\begin{array}{l}\text { compressive prism strength of masonry } \\
\text { compressive strength of mortar }\end{array}$ & $W_{y l}$ & $\begin{array}{l}\text { strength of masonry by using yield-line } \\
\text { method }\end{array}$ \\
\hline$f_{b}$ & compressive strength of brick & $W_{f l}$ & strength of masonry by using \\
\hline$f_{c}$ & compressive strength of concrete & & failure-line method \\
\hline$f_{m e}^{\prime}$ & compressive strength of member of truss & $W_{c s}$ & $\begin{array}{l}\text { strength of masonry by using } \\
\text { compressive strut method }\end{array}$ \\
\hline$f_{t p e}$ & $\begin{array}{l}\text { average out-of-plane } \\
\text { flexural tensile strength perpendicular }\end{array}$ & $W_{t}$ & $\begin{array}{l}\text { strength of masonry by using } \\
\text { FTM in tension }\end{array}$ \\
\hline $\begin{array}{l}f_{p} \\
\text { FTM }\end{array}$ & $\begin{array}{l}\text { compressive strength of unit masonry } \\
\text { fictitious truss method }\end{array}$ & $W_{c}$ & $\begin{array}{l}\text { strength of masonry by using } \\
\text { FTM in compression }\end{array}$ \\
\hline TMSD & fictitious truss method single diagonal & $y$ & distance from center of effective width of \\
\hline TMDD & fictitious truss method double diagonal & & a cross section of the masonry wall to \\
\hline $\mathrm{H}$ & height of masonry wall & & center of element top truss area \\
\hline$h_{t}$ & horizontal truss element & & \\
\hline$I_{e q}$ & $\begin{array}{l}\text { inertia unit equivalent of masonry element } \\
\text { inertia of element } n \text { equivalent of masonry }\end{array}$ & & \\
\hline$I_{n}$ & ement & & \\
\hline
\end{tabular}


413

414

415

416

417

418

419

420

421

422

423

424

425

426

427

428

429

430

431

432

433

434

435

436

437

\section{References}

[1] S. Noor-E-Khuda, M. Dhanasekar, and D. Thambiratnam. An explicit finite element modelling method for masonry walls under out-of-plane loading. Eng. Struct. 113 (2016) $103-120$.

[2] J. Gilstrap and C. Dolan. Out-of-plane bending of FRP-reinforced masonry walls. Compos. Sci. 58(8) (1998) 1277-1284.

[3] X. Zhang, S. Singh, D. Bull, and N. Cooke. Out-of-Plane Performance of Reinforced Masonry Walls with Openings. J. Struct. Eng.-ASCE 127(1) (2001) 51-57.

[4] R. Drysdale and A. Essawy. Out-of-Plane Bending of Concrete Block Walls. J. Struct. Eng.ASCE 114(1) (1988) 121-133.

[5] M. Griffith, J. Vaculik, Out-of-plane flexural strength of unreinforced clay brick masonry walls, TMS J. (2007).

[6] D. Abrams, R. Angel, and J. Uzarski. Out-of-Plane Strength of Unreinforced Masonry Infill Panels. Earthq. Spectra 12(4) (1996) 825-844.

[7] R. Henderson, K. Fricke, W. Jones, J. Beavers, and R. Bennett. Summary of a Large and Small-Scale Unreinforced Masonry Infill Test Program. J. Struct. Eng.-ASCE 129(12) (2003) 1667-1675.

[8] Y. Tu, T. Chuang, P. Liu, and Y. Yang. Out-of-plane shaking table tests on unreinforced masonry panels in RC frames. Eng. Struct. 32(12) (2010) 3925-3935.

[9] J. Varela-Rivera, D. Navarrete-Macias, L. Fernandez-Baqueiro, and E. Moreno. Out-of-plane behaviour of confined masonry walls. Eng. Struct. 33(5) (2011) 1734-1741.

[10] J. Varela-Rivera, J. Moreno-Herrera, I. Lopez-Gutierrez, and L. Fernandez-Baqueiro. Outof-Plane Strength of Confined Masonry Walls. J. Struct. Eng.-ASCE 138(11) (2012) 13311341. 
[11] J. Varela-Rivera, M. Polanco-May, L. Fernandez-Baqueiro, and E. Moreno. Confined masonry walls subjected to combined axial loads and out-of-plane uniform pressures. Can. J. Civil Eng. 39(4) (2012) 439-447.

[12] J. Moreno-Herrera, J. Varela-Rivera, and L. Fernandez-Baqueiro. Out-of-Plane Design Procedure for Confined Masonry Walls. J. Struct. Eng.-ASCE 142(2) (2016) 04015126.

[14] P. Agnihotri, V. Singhal, and D. Rai. Effect of in-plane damage on out-of-plane strength of 446

[15] L. La Mendola, M. Accardi, C. Cucchiara, and V. Licata. Nonlinear FE analysis of out-ofunreinforced masonry walls. Eng. Struct. 57 (2013) 1-11. plane behaviour of masonry walls with and without CFRP reinforcement. Constr. Build. Mater. 54 (2014) 190-196.

G. Milani, M. Pizzolato, and A. Tralli. Simple numerical model with second order effects for out-of-plane loaded masonry walls. Eng. Struct. 48 (2013) 98-120.

P. Asteris, L. Cavaleri, F. Di Trapani, and A. Tsaris. Numerical modelling of out-of-plane response of infilled frames: State of the art and future challenges for the equivalent strut macromodels. Eng. Struct. 132 (2017) 110-122.

L. Cavaleri, M. Fossetti, and M. Papia. Modeling of Out-of-Plane Behavior of Masonry Walls. J. Struct. Eng.-ASCE 135(12) (2009) 1522-1532.

[19] D. Dizhur, M. Griffith, and J. Ingham. Out-of-plane strengthening of unreinforced masonry walls using near surface mounted fibre reinforced polymer strips. Eng. Struct. 59 (2014) $330-343$.

[20] C. Willis, R. Seracino, and M. Griffith. Out-of-plane strength of brick masonry retrofitted with horizontal NSM CFRP strips. Eng. Struct. 32(2) (2010) 547-555.

[21] Ö. Anil, M. Tatayoğlu, and M. Demirhan. Out-of-plane behavior of unreinforced masonry brick walls strengthened with CFRP strips. Constr. Build. Mater. 35 (2012) 614-624. 
[22] N. Ismail and J. Ingham. In-plane and out-of-plane testing of unreinforced masonry walls strengthened using polymer textile reinforced mortar. Eng. Struct. 118 (2016) 167-177.

[23] A. Furtado, H. Rodrigues, A. Arêde, and H. Varum. Experimental evaluation of out-of-plane capacity of masonry infill walls. Eng. Struct. 111 (2016) 48-63.

[24] Y. Lu and M. Panagiotou. Three-Dimensional Cyclic Beam-Truss Model for Nonplanar Reinforced Concrete Walls. J. Struct. Eng.-ASCE 140(3) (2014) 04013071.

[25] M. Moharrami, I. Koutromanos, and M. Panagiotou. Nonlinear Truss Modeling Method for 471

[26] J. Almeida, P. Lourenco, and J. Barros. Characterization of brick and brick-mortar interface the Analysis of Shear Failures in Reinforced Concrete and Masonry Structures. Improving the Seismic Performance of Existing Buildings and Other Structures (2015) 74-85.

under uniaxial tension. VII International Seminar on Structural Masonry for Developing Countries (2002).

H. Kaushik, D. Rai, and S. Jain. Stress-Strain Characteristics of Clay Brick Masonry under Uniaxial Compression. J. Mater. Civ. Eng. 19(9) (2007) 728-739.

CEN 1999. Eurocode 6: Design of masonry structures- Part-1-1: General rules for reinforced and unreinforced masonry structures. European Committee for Standardization, 1 (2005) 125.

[29] S. Hamoush, M. McGinley, P. Mlakar, and M. Terro. Out-of-plane behavior of surfacereinforced masonry walls. Constr. Build. Mater. 16(6) (2002) 341-351.

[30] K. Martini. "Finite Element Studies in the Out-Of-Plane Failure of Unreinfored Masonry" Proc., 7th Int. Conf. on computing in Civil and Building Engineering, C. K. Choi, ed., Korea (1997) 179-184.

[31] SAP2000, Version 17.3.0 Build 1158. Structural Analysis Program. Berkeley, (CA), Computer and Structure, Inc. (2015).

[32] Standart Nasional Indonesia SNI 03-2847-2013. Persyaratan Beton Struktural untuk Bangunan Gedung. Badan Standarisasi Nasional (BSN), Jakarta, 2013. 
[33] J. Dawe, C. Seah Out-of-plane resistance of concrete masonry infilled panels.

491 Canadian Journal of Civil Engineering. 1989;16(6):854-864

492 


\section{Table captions}

2 Table 1. Methods of analyzing masonry structures under out-of-plane loading

3 Table 2. Geometry, aspect ratio, and slenderness ratio of wall specimens

4 Table 3. Properties of SikaWrap 230-C (unidirectional) CFRP and Sikadur 330 resin

5 Table 4. Comparison of FTM with Varela Rivera's experimental results and various analysis 6 methods

7 Table 5. Percentage of error of FTM method relative to Varela Rivera's experiment and analysis 8 method results

9 Table 6. Comparison of FTM relative to Hamoush's experiment

10 Table 7. Comparison of FTM to Anil' experiment and analysis results 
12 Table 1. Methods of analyzing masonry structures under out-of-plane loading

\begin{tabular}{lll}
\hline Analysis Method & Reference. \\
\hline Yield line method & unreinforced wall & {$[4],[30]$} \\
& $\begin{array}{l}\text { reinforced wall } \\
\text { confined wall }\end{array}$ & {$[3]$} \\
& unreinforced wall & {$[4]$} \\
\hline The failure line method & unconfined wall & {$[9-11]$} \\
& surrounded by steel frame & Dawe and Seah [33] cited from \\
The modified yielding line method & {$[12]$} \\
\hline The compressive strut method & confined wall & {$[9-10]$} \\
& infill walls & {$[6]$} \\
\hline $\begin{array}{l}\text { The spring-strut and the } \\
\text { bidirectional strut method }\end{array}$ & confined walls & {$[9-12]$} \\
\hline
\end{tabular}

13

14 
16 Table 2. Geometry, aspect ratio, and slenderness ratio of wall specimens

\begin{tabular}{ccccccccccccc}
\hline $\begin{array}{c}\text { Wall } \\
\text { specimen }\end{array}$ & $\begin{array}{c}f_{c} \\
(\mathrm{MPa})\end{array}$ & $\begin{array}{c}f_{j} \\
(\mathrm{MPa})\end{array}$ & $\begin{array}{c}f_{p} \\
(\mathrm{MPa})\end{array}$ & $\begin{array}{c}f_{m} \\
(\mathrm{MPa})\end{array}$ & $\begin{array}{c}f_{\text {tpe }} \\
(\mathrm{MPa})\end{array}$ & $\begin{array}{c}f_{\text {tpa }} \\
(\mathrm{MPa})\end{array}$ & $\begin{array}{c}E_{c} \\
(\mathrm{MPa})\end{array}$ & $\begin{array}{c}\text { Length } \\
L(\mathrm{~m})\end{array}$ & $\begin{array}{c}\text { Height } \\
H(\mathrm{~m})\end{array}$ & $\begin{array}{c}\text { Thickness } \\
t(\mathrm{~m})\end{array}$ & $H / L$ & $H / t$ \\
\hline E-1 & 14.79 & 2.89 & 5.47 & 2.84 & 0.14 & 0.44 & 9,614 & 3.67 & 2.72 & 0.15 & 0.74 & 18.13 \\
E-2 & 19.16 & 2.34 & 5.47 & 2.84 & 0.14 & 0.44 & 10,943 & 3.77 & 2.88 & 0.15 & 0.76 & 19.20 \\
E-3 & 19.80 & 2.47 & 4.09 & 2.45 & 0.11 & 0.36 & 11,124 & 3.77 & 2.88 & 0.12 & 0.76 & 24.00 \\
E-4 & 15.31 & 2.79 & 5.47 & 2.84 & 0.14 & 0.44 & 9,782 & 2.85 & 2.72 & 0.15 & 0.95 & 18.13 \\
E-5 & 17.39 & 2.66 & 5.47 & 2.84 & 0.14 & 0.44 & 10,425 & 2.95 & 2.72 & 0.15 & 0.92 & 18.13 \\
E-6 & 21.67 & 2.26 & 4.09 & 2.45 & 0.11 & 0.36 & 11,638 & 2.95 & 2.72 & 0.12 & 0.92 & 22.67 \\
\hline
\end{tabular}

17 Data taken from Varela-Rivera et al. [9]

18

19 
Table 3. Properties of SikaWrap 230-C (unidirectional) CFRP and Sikadur 330 resin

\begin{tabular}{lll}
\cline { 2 - 3 } 21 & Properties of CFRP & Remarks of CFRP \\
22 & Thickness (mm) & 0.12 \\
23 & Tensile strength (MPa) & 4100 \\
24 & Elastic modulus (MPa) & 231,000 \\
25 & Ultimate tensile strain $(\%)$ & $1.7 \%$ \\
26 & Properties of resin & Remarks of resin \\
27 & Tensile strength (MPa) & 30 \\
28 & Elastic modulus (MPa) & 3800 \\
\hline
\end{tabular}

29 (Data taken from Anil et al. [21])

30 
31 Table 4. Comparison of FTM with Varela Rivera's experimental results and various analysis 32 methods

\begin{tabular}{|c|c|c|c|c|c|c|c|}
\hline \multicolumn{2}{|c|}{ Wall specimen $(\mathrm{kPa})$} & E-1 & E-2 & E-3 & E-4 & E-5 & E-6 \\
\hline \multicolumn{2}{|c|}{$W_{e}$ (Varela Rivera experiment) } & 8.79 & 13.01 & 12.01 & 14.53 & 17.83 & 15.40 \\
\hline \multicolumn{2}{|c|}{$W_{y l}($ Yield line method $)$} & 7.01 & 7.18 & 3.74 & 9.31 & 9.35 & 4.89 \\
\hline \multicolumn{2}{|c|}{$W_{f l}$ (Failure line method) } & 6.21 & 6.33 & 3.30 & 8.71 & 8.75 & 4.57 \\
\hline \multicolumn{2}{|c|}{$W_{c s}($ Compressive strut method $)$} & 38.55 & 38.55 & 17.33 & 33.21 & 33.21 & 14.93 \\
\hline \multicolumn{2}{|c|}{$W_{s s}($ Spring strut method) } & 6.57 & 30.42 & 11.91 & 15.39 & 30.08 & 11.54 \\
\hline \multirow{4}{*}{$\begin{array}{c}\text { Double } \\
\text { Diagonal }\end{array}$} & $W_{t}($ FTMDD ) & 9.85 & 7.23 & 4.56 & 9.51 & 9.00 & 4.44 \\
\hline & $\delta .(\mathrm{mm})$ & 13.22 & 14.89 & 18.72 & 12.82 & 12.26 & 15.07 \\
\hline & $W_{c}(\mathrm{FTMDD})$ & 14.76 & 11.46 & 8.05 & 14.26 & 13.48 & 8.03 \\
\hline & $\delta .(\mathrm{mm})$ & 19.81 & 23.60 & 33.08 & 19.21 & 18.37 & 27.30 \\
\hline \multirow{4}{*}{$\begin{array}{c}\text { Single } \\
\text { Diagonal }\end{array}$} & $W_{t}(\mathrm{FTMSD})$ & 9.13 & 6.78 & 4.40 & 8.82 & 8.38 & 4.27 \\
\hline & $\delta .(\mathrm{mm})$ & 12.67 & 14.29 & 17.08 & 12.28 & 11.81 & 14.88 \\
\hline & $W_{c}(\mathrm{FTMSD})$ & 15.42 & 11.94 & 8.30 & 14.89 & 14.09 & 8.24 \\
\hline & $\delta .(\mathrm{mm})$ & 21.40 & 25.15 & 32.27 & 20.74 & 19.85 & 28.73 \\
\hline
\end{tabular}


Table 5. Percentage of error of FTM method relative to Varela Rivera's experiment and analysis method results

\begin{tabular}{ccccccc}
\hline Wall specimen $(\mathrm{kPa})$ & E-1 & E-2 & E-3 & E-4 & E-5 & E-6 \\
\hline We (Varela Rivera experiment) & 8.79 & 13.01 & 12.01 & 14.53 & 17.83 & 15.40 \\
\hline Wt (FTMDD ) & 9.85 & 7.23 & 4.56 & 9.51 & 9.00 & 4.44 \\
\% of error & $\mathbf{1 2 . 0 6}$ & 44.41 & 62.06 & 34.53 & 49.53 & 71.20 \\
\hline Wt (FTMSD ) & 9.13 & 6.78 & 4.40 & 8.82 & 8.38 & 4.27 \\
\% of error & $\mathbf{3 . 8 5}$ & 47.88 & 63.40 & 39.33 & 52.98 & 72.27 \\
\hline Wc (FTMDD) & 14.76 & 11.46 & 8.05 & 14.26 & 13.48 & 8.03 \\
\% of error & 67.95 & $\mathbf{1 1 . 8 8}$ & 32.95 & $\mathbf{1 . 8 8}$ & $\mathbf{2 4 . 3 8}$ & 47.83 \\
\hline Wc (FTMSD) & 15.42 & 11.94 & 8.30 & 14.89 & 14.09 & 8.24 \\
\% of error & 75.4 & $\mathbf{8 . 3}$ & 30.9 & $\mathbf{2 . 5}$ & $\mathbf{2 0 . 9}$ & 46.5 \\
\hline
\end{tabular}

Yield line method

\begin{tabular}{ccccccc}
\hline Wall specimen & E-1 & E-2 & E-3 & E-4 & E-5 & E-6 \\
\hline Wyl (Yield line method) & 7.01 & 7.18 & 3.74 & 9.31 & 9.35 & 4.89 \\
\hline Wt (FTMDD ) & 9.85 & 7.23 & 4.56 & 9.51 & 9.00 & 4.44 \\
\% of error & 40.52 & $\mathbf{0 . 7 2}$ & $\mathbf{2 1 . 8 3}$ & $\mathbf{2 . 1 8}$ & $\mathbf{3 . 7 6}$ & $\mathbf{9 . 2 9}$ \\
\hline Wt (FTMSD ) & 9.13 & 6.78 & 4.40 & 8.82 & 8.38 & 4.27 \\
\% of error & 30.22 & $\mathbf{5 . 5 6}$ & $\mathbf{1 7 . 5 4}$ & $\mathbf{5 . 3 1}$ & $\mathbf{1 0 . 3 3}$ & $\mathbf{1 2 . 6 9}$ \\
\hline Wc (FTMDD) & 14.76 & 11.46 & 8.05 & 14.26 & 13.48 & 8.03 \\
\% of error & 110.60 & 59.67 & 115.33 & 53.13 & 44.20 & 64.30 \\
\hline Wc (FTMSD) & 15.42 & 11.94 & 8.30 & 14.89 & 14.09 & 8.24 \\
\% of error & 119.95 & 66.23 & 122.06 & 59.92 & 50.75 & 68.52 \\
\hline
\end{tabular}

Failure line method

\begin{tabular}{ccccccc}
\hline Wall specimen & E-1 & E-2 & E-3 & E-4 & E-5 & E-6 \\
\hline Wfl (Failure line method) & 6.21 & 6.33 & 3.30 & 8.71 & 8.75 & 4.57 \\
\hline Wt (FTMDD ) & 9.85 & 7.23 & 4.56 & 9.51 & 9.00 & 4.44 \\
\% of error & 58.62 & $\mathbf{1 4 . 2 5}$ & 38.08 & $\mathbf{9 . 2 2}$ & $\mathbf{2 . 8 4}$ & $\mathbf{2 . 9 4}$ \\
\hline Wt (FTMSD ) & 9.13 & 6.78 & 4.40 & 8.82 & 8.38 & 4.27 \\
\% of error & 47.00 & $\mathbf{7 . 1 3}$ & 33.21 & $\mathbf{1 . 2 2}$ & $\mathbf{4 . 1 8}$ & $\mathbf{6 . 5 7}$ \\
\hline Wc (FTMDD) & 14.76 & 11.46 & 8.05 & 14.26 & 13.48 & 8.03 \\
\% of error & 137.73 & 81.11 & 144.04 & 63.68 & 54.09 & 75.80 \\
\hline Wc (FTMSD) & 15.42 & 11.94 & 8.30 & 14.89 & 14.09 & 8.24 \\
\% of error & 148.28 & 88.55 & 151.66 & 70.94 & 61.08 & 80.32 \\
\hline
\end{tabular}

Compressive strut method

\begin{tabular}{ccccccc}
\hline Wall specimen & E-1 & E-2 & E-3 & E-4 & E-5 & E-6 \\
\hline Wcs (Compressive strut method) & 38.55 & 38.55 & 17.33 & 33.21 & 33.21 & 14.93 \\
\hline
\end{tabular}




\begin{tabular}{ccccccc}
\hline Wt (FTM DD ) & 9.85 & 7.23 & 4.56 & 9.51 & 9.00 & 4.44 \\
\% of error & 74.4 & 81.2 & 73.7 & 71.4 & 72.9 & 70.3 \\
\hline Wt (FTM SD ) & 9.13 & 6.78 & 4.40 & 8.82 & 8.38 & 4.27 \\
\% of error & 76.3 & 82.4 & 74.6 & 73.5 & 74.8 & 71.4 \\
\hline Wc (FTM DD) & 14.76 & 11.46 & 8.05 & 14.26 & 13.48 & 8.03 \\
\% of error & 61.7 & 70.3 & 53.5 & 57.1 & 59.4 & 46.2 \\
\hline Wc (FTM SD) & 15.42 & 11.94 & 8.30 & 14.89 & 14.09 & 8.24 \\
\% of error & 60.0 & 69.0 & 52.1 & 55.2 & 57.6 & 44.8 \\
\hline
\end{tabular}

Spring strut method

\begin{tabular}{ccccccc}
\hline Wall specimen & E-1 & E-2 & E-3 & E-4 & E-5 & E-6 \\
\hline Wss (Spring strut method) & 6.57 & 30.42 & 11.91 & 15.39 & 30.08 & 11.54 \\
\hline Wt (FTM DD ) & 9.85 & 7.23 & 4.56 & 9.51 & 9.00 & 4.44 \\
\% of error & 49.93 & 76.23 & 61.74 & 38.19 & 70.08 & 61.56 \\
\hline Wt (FTM SD ) & 9.13 & 6.78 & 4.40 & 8.82 & 8.38 & 4.27 \\
\% of error & 38.95 & 77.71 & 63.09 & 42.72 & 72.13 & 63.00 \\
\hline Wc (FTM DD) & 14.76 & 11.46 & 8.05 & 14.26 & 13.48 & 8.03 \\
\% of error & 124.70 & 62.31 & 32.38 & $\mathbf{7 . 3 7}$ & 55.18 & 30.38 \\
\hline Wc (FTM SD) & 15.42 & 11.94 & 8.30 & 14.89 & 14.09 & 8.24 \\
\% of error & 134.68 & 60.76 & 30.27 & $\mathbf{3 . 2 6}$ & 53.14 & $\mathbf{2 8 . 5 9}$ \\
\hline
\end{tabular}


40 Table 6. Comparison of FTM relative to Hamoush's experiment

\begin{tabular}{|c|c|c|c|c|c|c|c|c|c|c|c|c|}
\hline & \multicolumn{12}{|c|}{ Distance of fiber to support } \\
\hline & \multicolumn{2}{|c|}{$2 \mathrm{~L}-\mathrm{d} / 4$} & \multicolumn{2}{|c|}{$2 \mathrm{~L}-\mathrm{d} / 2$} & \multicolumn{2}{|c|}{ 2L-0 } & \multicolumn{2}{|c|}{$1 \mathrm{~L}-\mathrm{d} / 4$} & \multicolumn{2}{|c|}{$1 \mathrm{~L}-0$} & \multicolumn{2}{|c|}{$1 \mathrm{~L}-\mathrm{d} / 2$} \\
\hline & $\begin{array}{c}\text { Max. } \\
\text { load } \\
\mathrm{kN}\end{array}$ & $\begin{array}{c}\delta . \\
\mathrm{mm}\end{array}$ & $\begin{array}{c}\text { Max. } \\
\text { load } \\
\mathrm{kN}\end{array}$ & $\begin{array}{c}\delta . \\
\mathrm{mm}\end{array}$ & $\begin{array}{c}\text { Max. } \\
\text { load } \\
\mathrm{kN}\end{array}$ & $\begin{array}{c}\delta . \\
\mathrm{mm}\end{array}$ & $\begin{array}{c}\text { Max. } \\
\text { load } \\
\text { kN }\end{array}$ & $\begin{array}{c}\delta . \\
\mathrm{mm}\end{array}$ & $\begin{array}{c}\text { Max. } \\
\text { load } \\
\mathrm{kN}\end{array}$ & $\begin{array}{c}\delta . \\
\mathrm{mm}\end{array}$ & $\begin{array}{c}\text { Max. } \\
\text { load } \\
\mathrm{kN}\end{array}$ & $\begin{array}{c}\delta . \\
\mathrm{mm}\end{array}$ \\
\hline$\overline{\text { Spec. } 1}$ & 65.84 & 2.47 & 49.84 & 3.33 & 41.23 & 2.69 & 47.17 & 2.87 & 45.14 & 4.05 & 51.6 & 2.75 \\
\hline Spec. 2 & 51.17 & 2.10 & 55.95 & 2.71 & 46.49 & 3.22 & 49.80 & 3.76 & 56.41 & 2.60 & 57.97 & 3.23 \\
\hline Spec. 3 & 40.21 & 1.75 & 52.59 & 4.49 & 53.69 & 3.53 & 48.99 & 3.25 & 49.94 & 3.05 & 47.58 & 2.76 \\
\hline Average & 52.41 & 2.11 & 52.79 & 3.51 & 47.14 & 3.15 & 48.65 & 3.29 & 50.50 & 3.23 & 52.38 & 2.91 \\
\hline FTMSD & 59.93 & 3.17 & 60.00 & 3.38 & 59.87 & 3.34 & 59.93 & 3.17 & 59.96 & 5.36 & 60.00 & 5.48 \\
\hline$\%$ of error & 14.35 & 50.43 & 13.65 & 3.62 & 27.01 & 6.13 & 23.17 & 3.77 & 18.75 & 65.71 & 14.55 & 88.08 \\
\hline FTMDD & 53.53 & 2.62 & 53.43 & 2.63 & 53.13 & 2.63 & 49.06 & 3.67 & 48.93 & 3.69 & 48.81 & 3.72 \\
\hline$\%$ of error & 2.15 & 24.15 & 1.21 & 25.20 & 12.72 & 16.50 & 0.83 & 11.42 & 3.10 & 14.22 & 6.82 & 27.84 \\
\hline
\end{tabular}

41 
43 Table 7. Comparison of FTM to Anil' experiment and analysis results

\begin{tabular}{|c|c|c|c|c|c|c|c|c|c|c|}
\hline & \multicolumn{2}{|c|}{ Anil's-1 } & \multicolumn{2}{|c|}{ Anil's-8 } & \multicolumn{2}{|c|}{ Anil's-9 } & \multicolumn{2}{|c|}{ Anil's-10 } & \multicolumn{2}{|c|}{ Anil's-11 } \\
\hline & $\begin{array}{c}\text { Load } \\
\mathrm{kN}\end{array}$ & $\begin{array}{c}\delta . \\
\mathrm{mm}\end{array}$ & $\begin{array}{c}\text { Load } \\
\mathrm{kN}\end{array}$ & $\begin{array}{c}\delta . \\
\mathrm{mm}\end{array}$ & $\begin{array}{c}\text { Load } \\
\mathrm{kN}\end{array}$ & $\begin{array}{c}\delta . \\
\mathrm{mm}\end{array}$ & $\begin{array}{c}\text { Load } \\
\mathrm{kN}\end{array}$ & $\begin{array}{c}\delta . \\
\mathrm{mm}\end{array}$ & $\begin{array}{c}\text { Load } \\
\mathrm{kN}\end{array}$ & $\begin{array}{c}\delta . \\
\mathrm{mm}\end{array}$ \\
\hline Anil's experiment & 1.76 & 0.91 & 16.47 & 8.14 & 14.50 & 5.83 & 11.74 & 7.10 & 19.71 & 10.93 \\
\hline Anil's Analysis & - & & 25.28 & & 25.28 & & 20.51 & & 20.51 & \\
\hline FTMSD & 2.16 & 3.72 & 16.48 & 24.56 & 16.71 & 23.32 & 10.10 & 20.77 & 17.70 & 33.15 \\
\hline$\%$ of error & 22.67 & & 0.07 & & 15.22 & & 13.98 & & 10.18 & \\
\hline FTMDD & 1.84 & 3.58 & 16.28 & 29.05 & 16.86 & 22.66 & 9.60 & 22.75 & 16.14 & 31.19 \\
\hline$\%$ of error & 4.27 & & 1.16 & & 16.28 & & 18.21 & & 18.09 & \\
\hline
\end{tabular}

44

45 


\section{Figure captions}

2 Figure 1. Establishing truss blocks and configuring the truss structure.

$3 \quad$ Figure 2. Truss shapes.

4 Figure 3. Determination of the effective height of a truss element.

$5 \quad$ Figure 4. Equivalent inertia of the effective cross section.

6 Figure 5. Schematic of the proposed FTM.

7 Figure 6. Stress-strain relationship of truss elements representing masonry walls

8 Figure 7. Setup of air bag (source Herrera et al. [12])

$9 \quad$ Figure 8. FTM model for Varela Rivera's setup

10 Figure 9. Comparison of results for the first validation experiment 
11 Figure 10. Hamoush's test setup and FTM model.

12 Figure 11. Comparison of results for the second validation experiment.

13 Figure 12. Anil's test setup and FTM model

14 Figure 13. Comparison of results for the third validation experiment.

15

16 

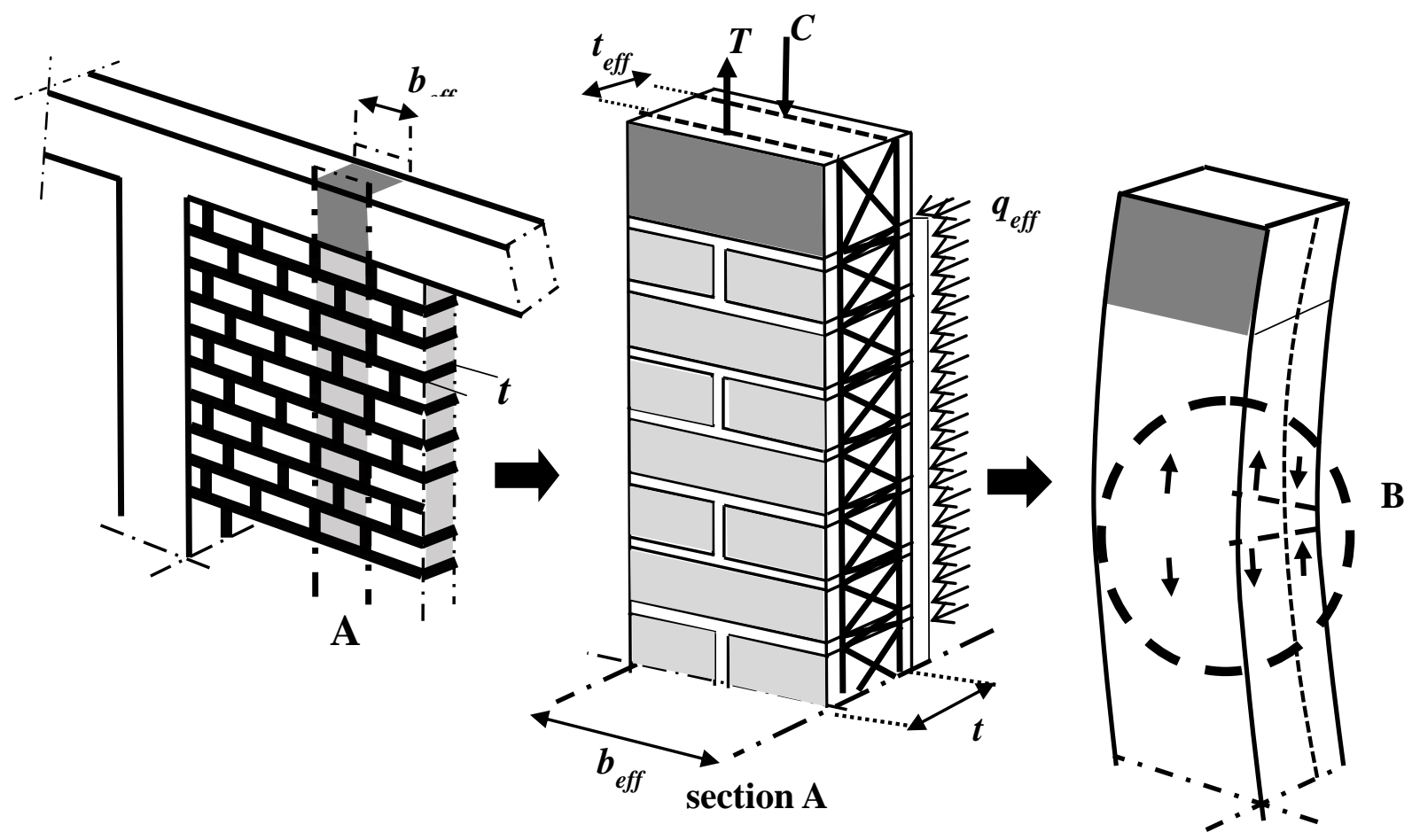

21 Figure 1. Establishing truss blocks and configuring the truss structure.

section B

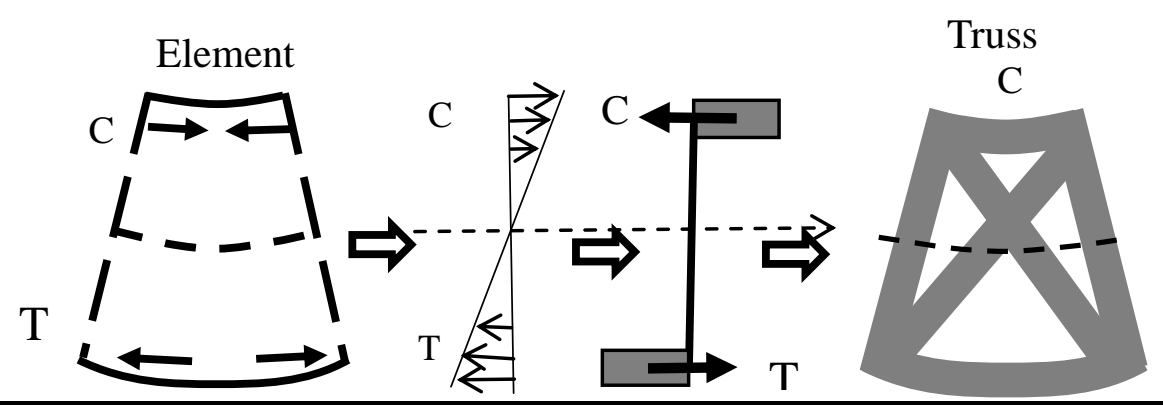




$$
\nabla \square
$$


27

28

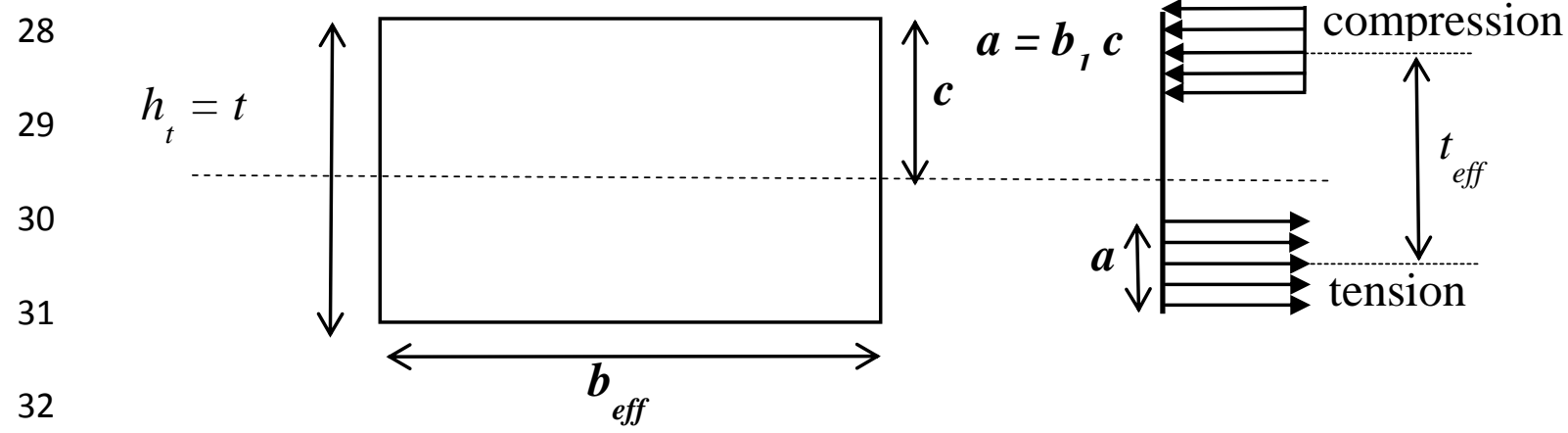

33 Figure 3. Determination of the effective height of a truss element.

34 


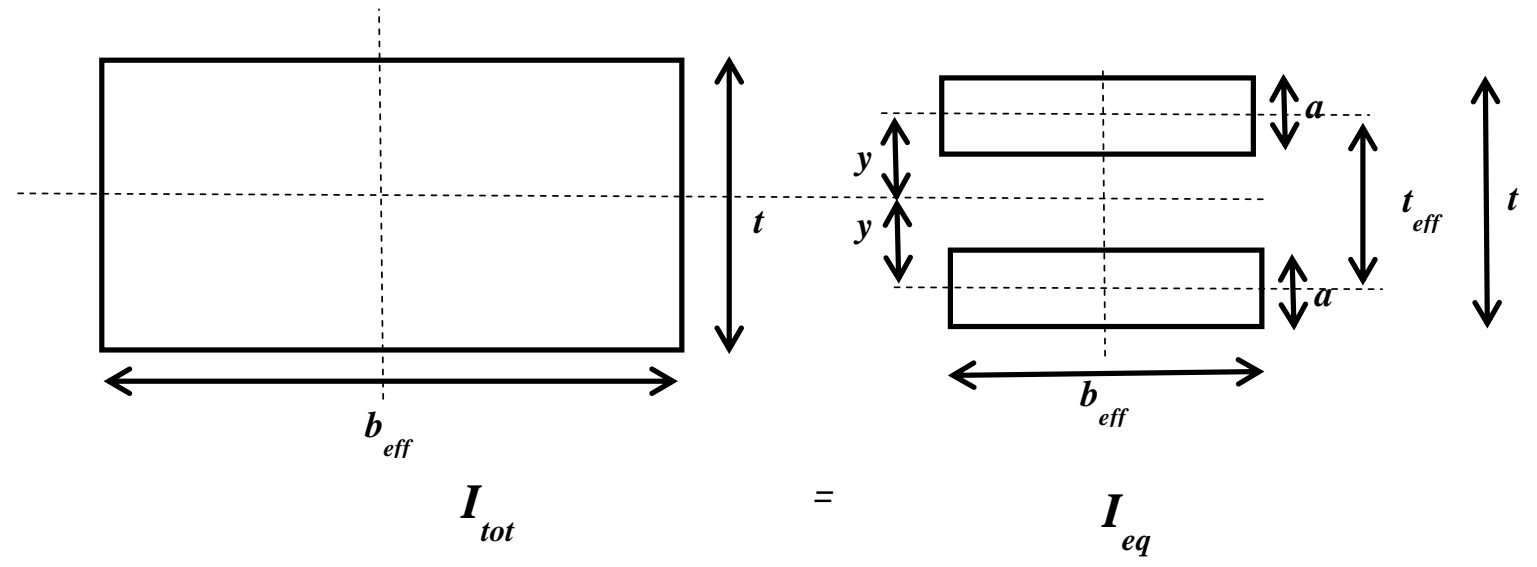

36

37

38 Figure 4. Equivalent inertia of the effective cross section.

39 


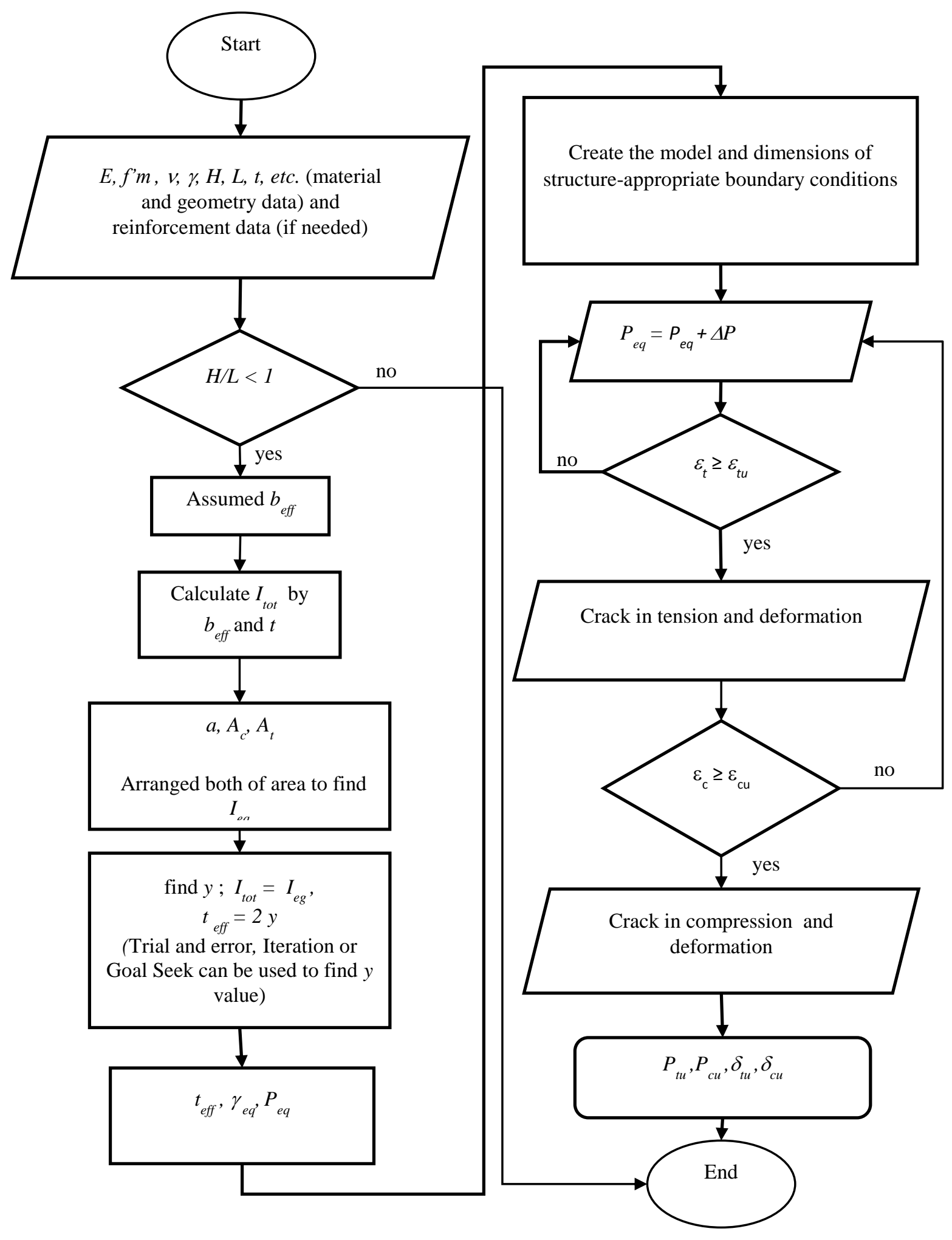


42 Figure 5. Schematic of the proposed FTM.

43

44
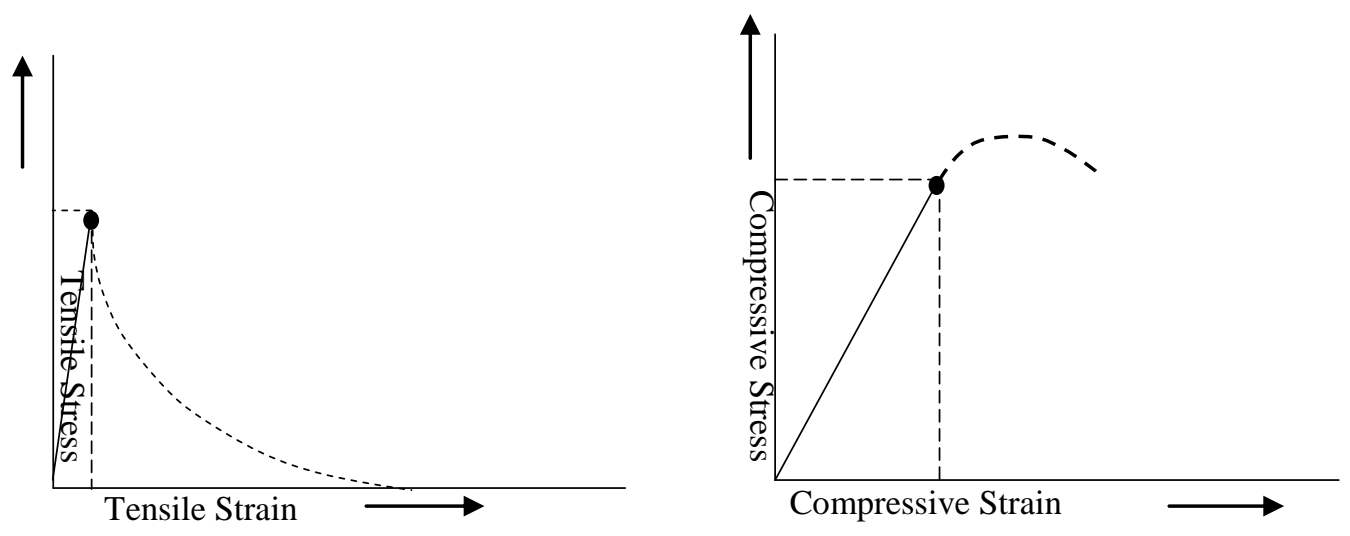

45 Figure 6. Stress-strain relationship of truss elements representing masonry walls 46 


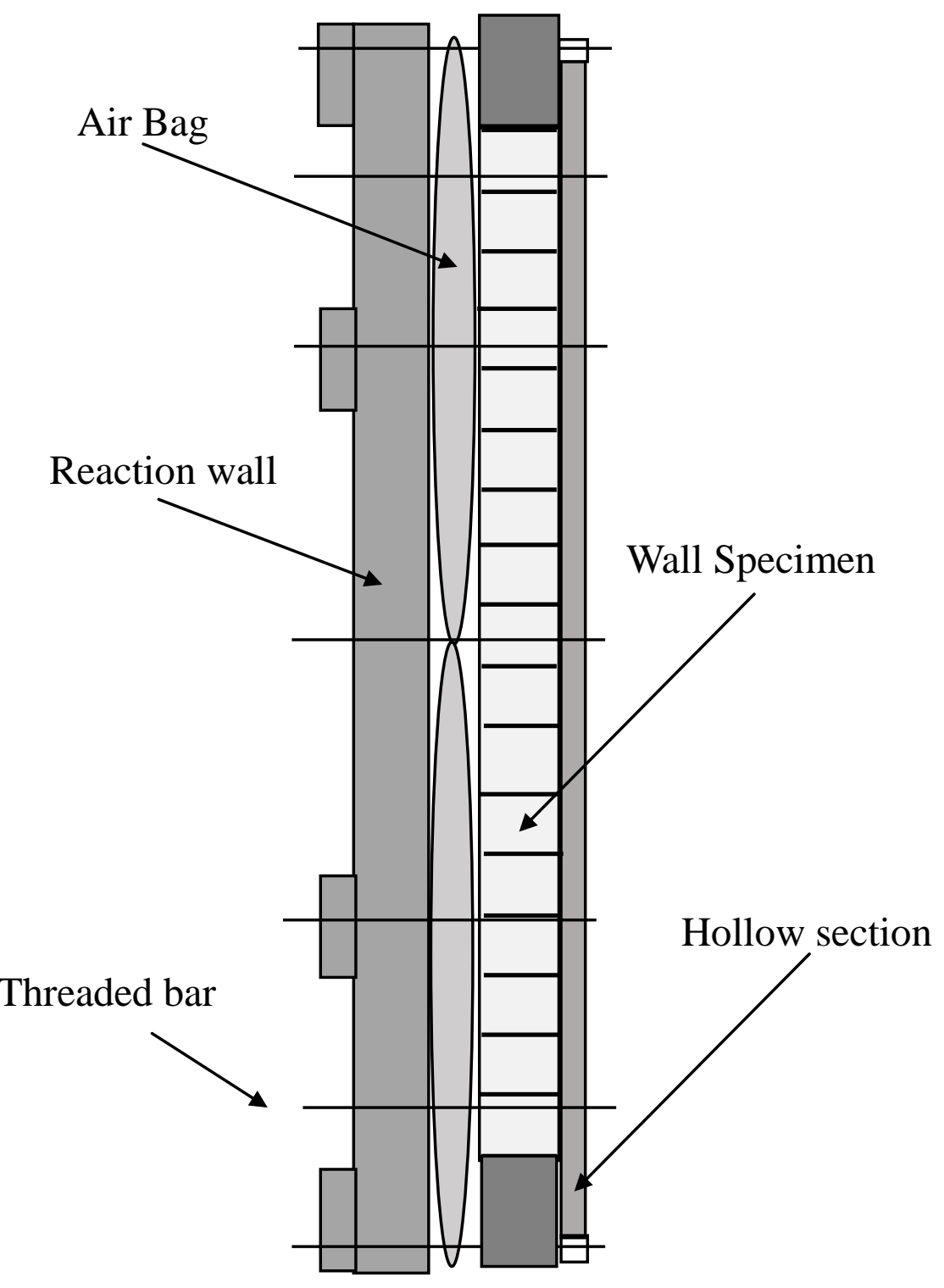

47

48 Figure 7. Setup of air bag (source Herrera et al. [12])

49 


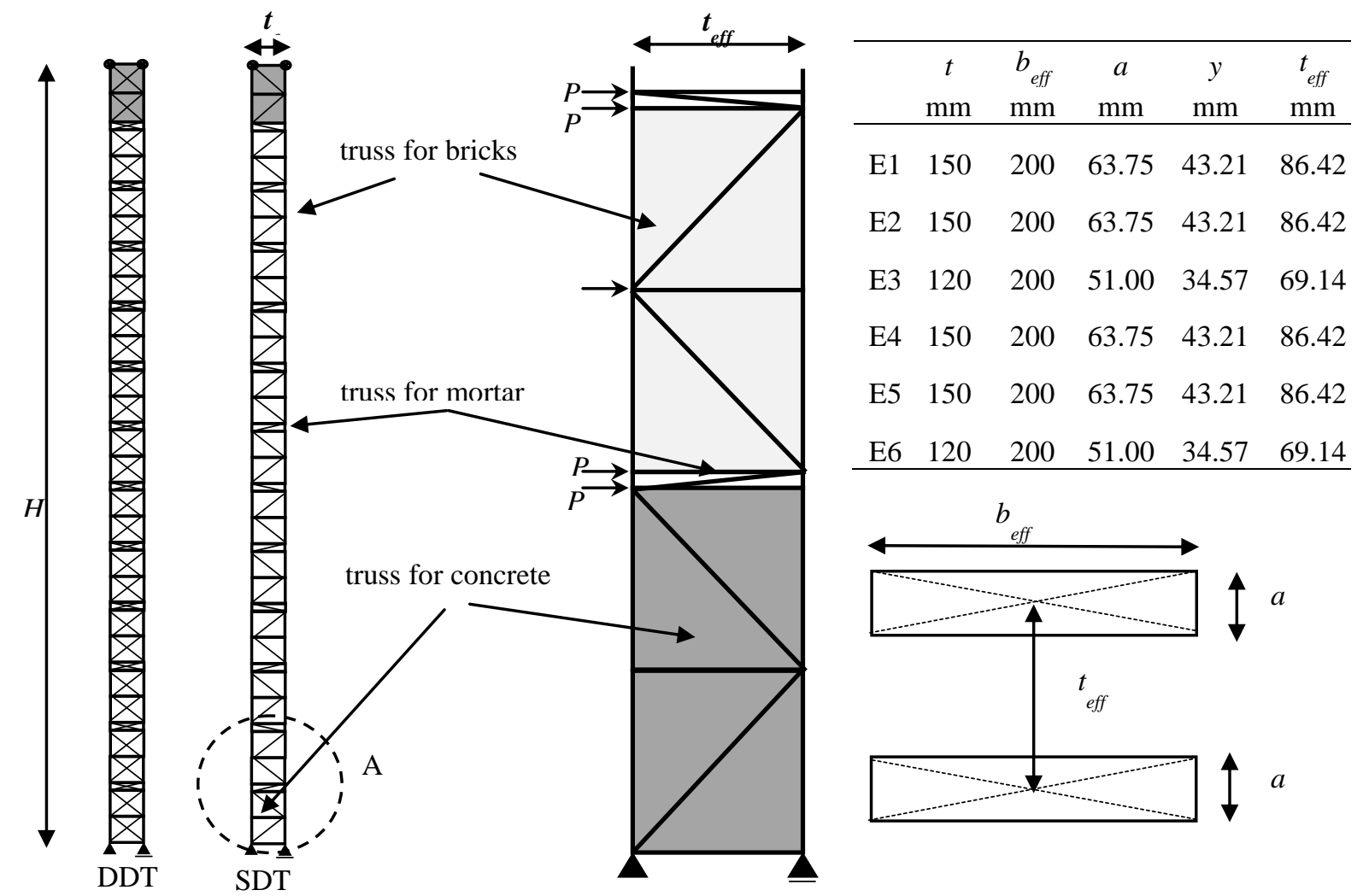

Section A

50

51 Figure 8. FTM model for Varela Rivera's setup

52 


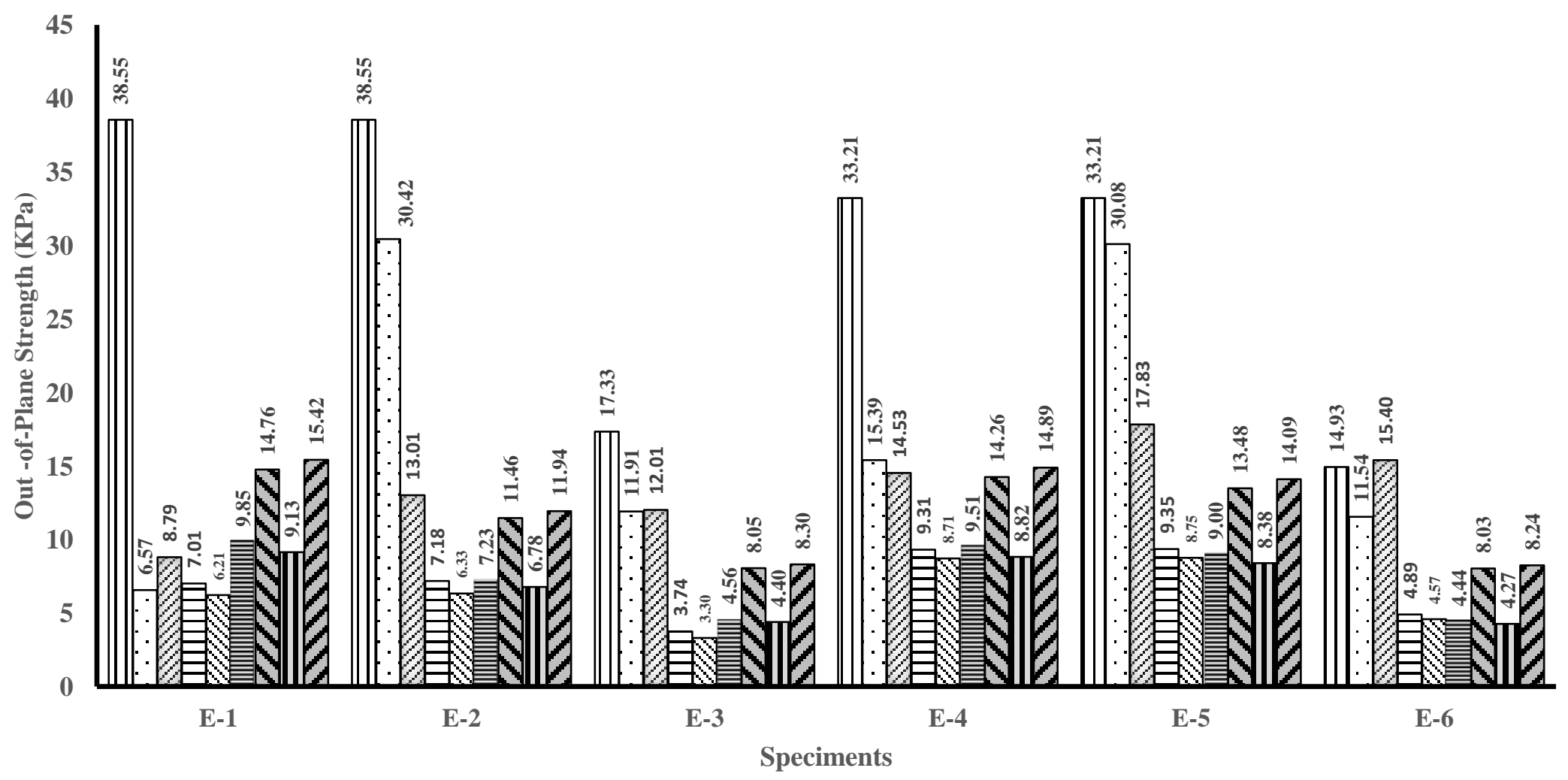
$\mathbf{u W c s}$ (Compressive strut method)
$\square$ Wss (Spring strut method)
$\square$ We (Varela Rivera experiment)
曰Wyl (Yield line method)
$\mathbf{W}$ Wfl (Failure line method)
目Wt (FTM DD )
घWc (FTM DD)
mWt (FTM SD )
Wc (FTM SD) 


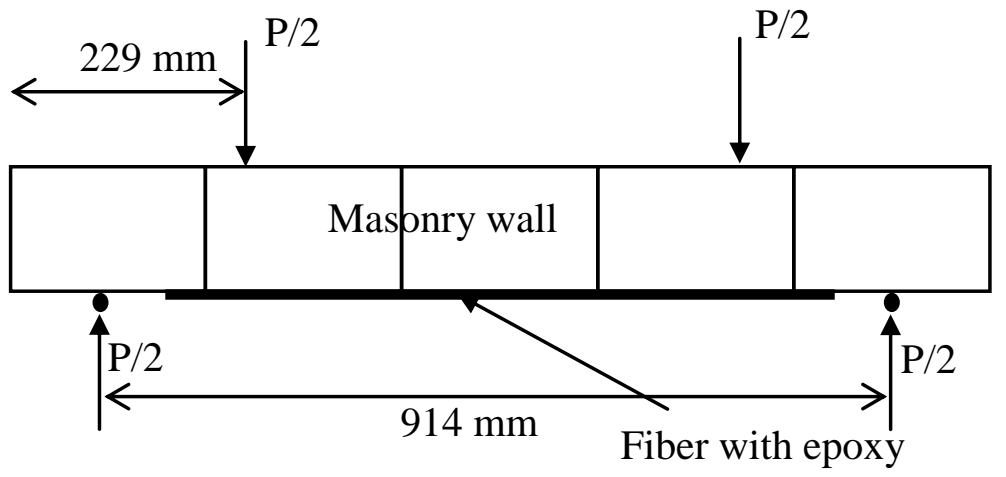

55

a. Hamoush test setup

56 

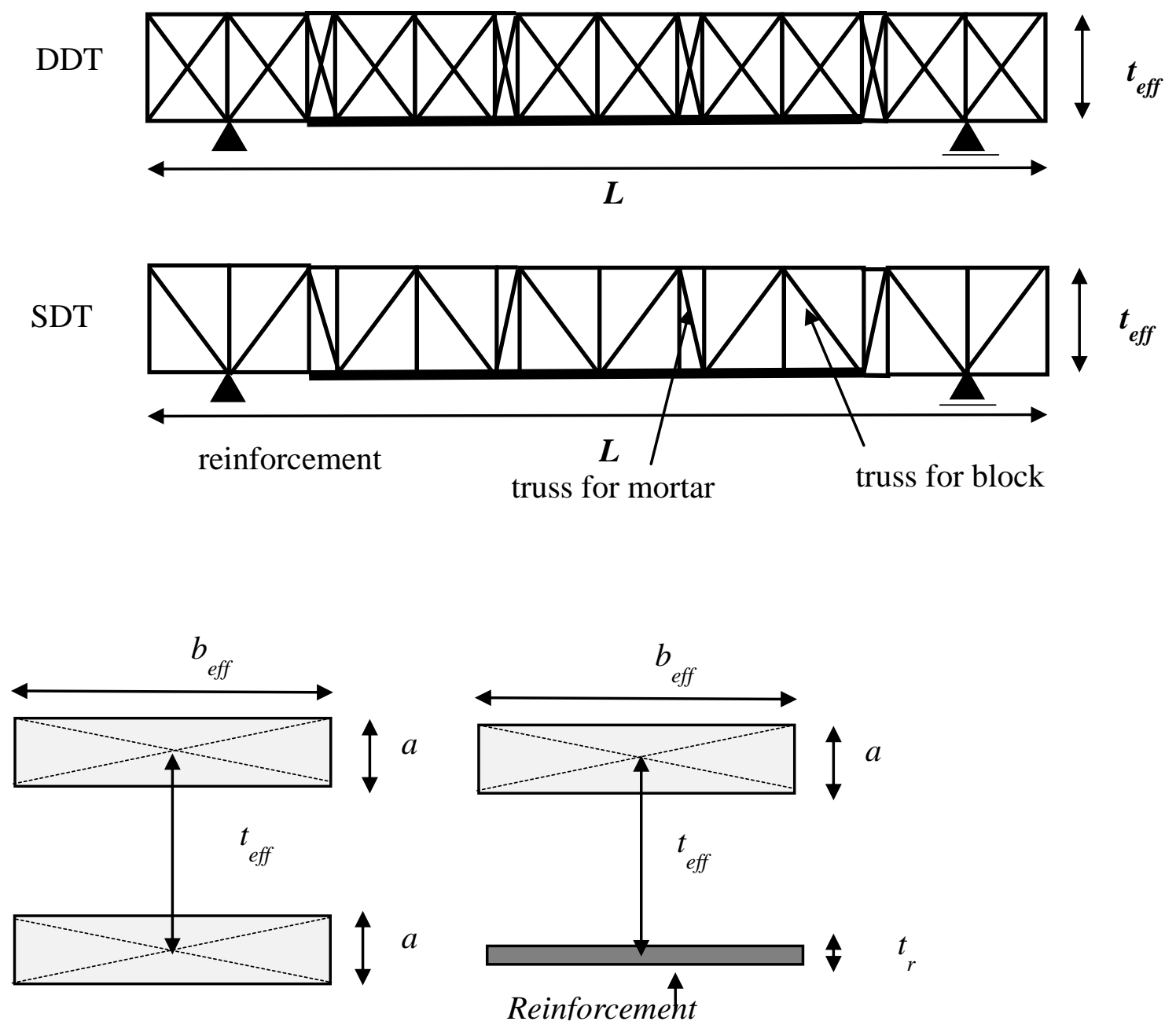

\begin{tabular}{ccccccc}
\hline$L(\mathrm{~mm})$ & $H(\mathrm{~mm})$ & $t(\mathrm{~mm})$ & $b_{\text {eff }}(\mathrm{mm})$ & $a(\mathrm{~mm})$ & $y(\mathrm{~mm})$ & $t_{\text {eff }}(\mathrm{mm})$ \\
\hline 600 & 900 & 200 & 200 & 85.00 & 38.89 & 77.78 \\
\hline
\end{tabular}

60

61

b. FTM model

62 Figure 10. Hamoush's test setup and FTM model.

63

64 


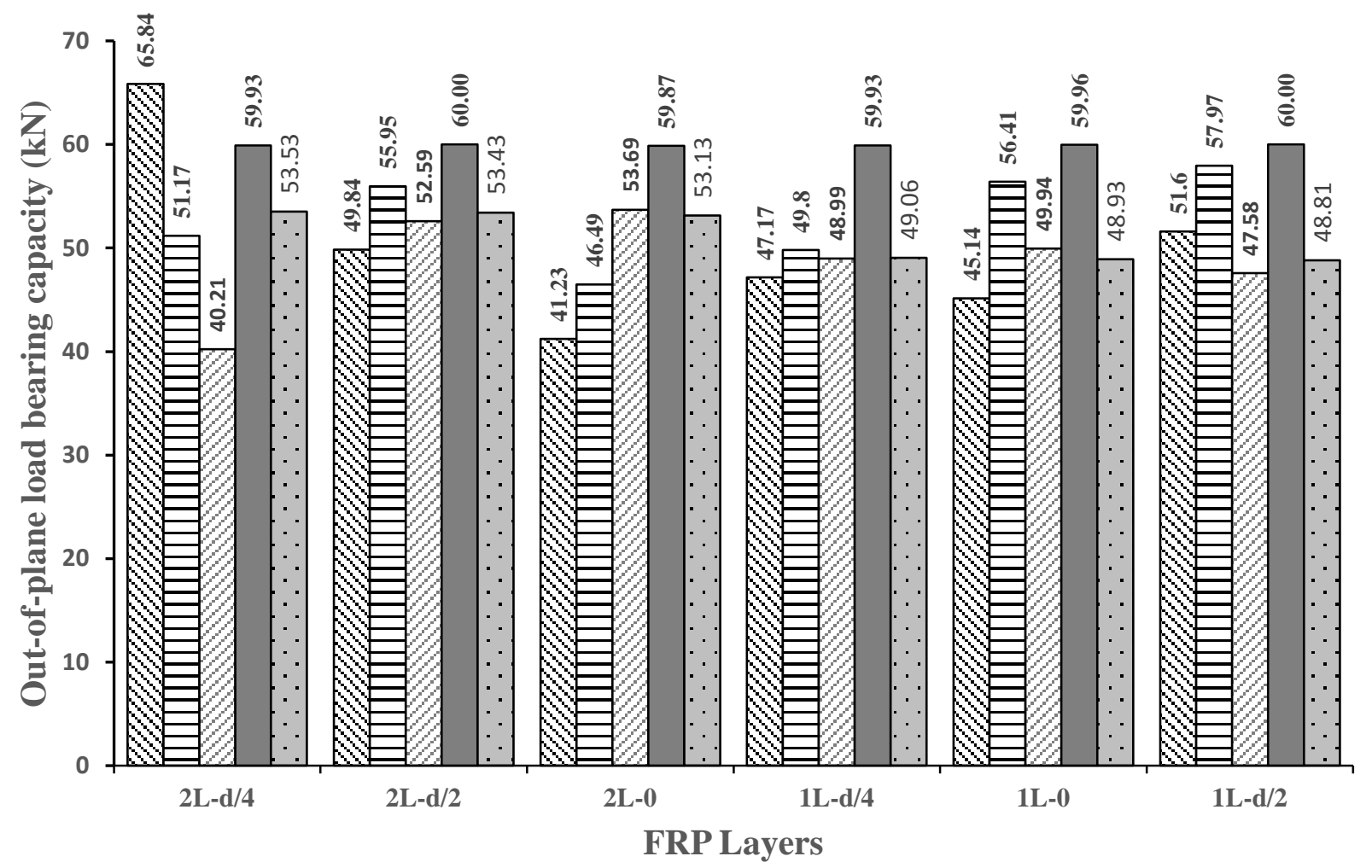

$₫$ Spec.1 $\quad \square$ Spec.2 $\square$ Spec.3 $\quad$ GTM SDT $\square$ FTM DDT

Figure 11. Comparison of results for the second validation experiment.

67 


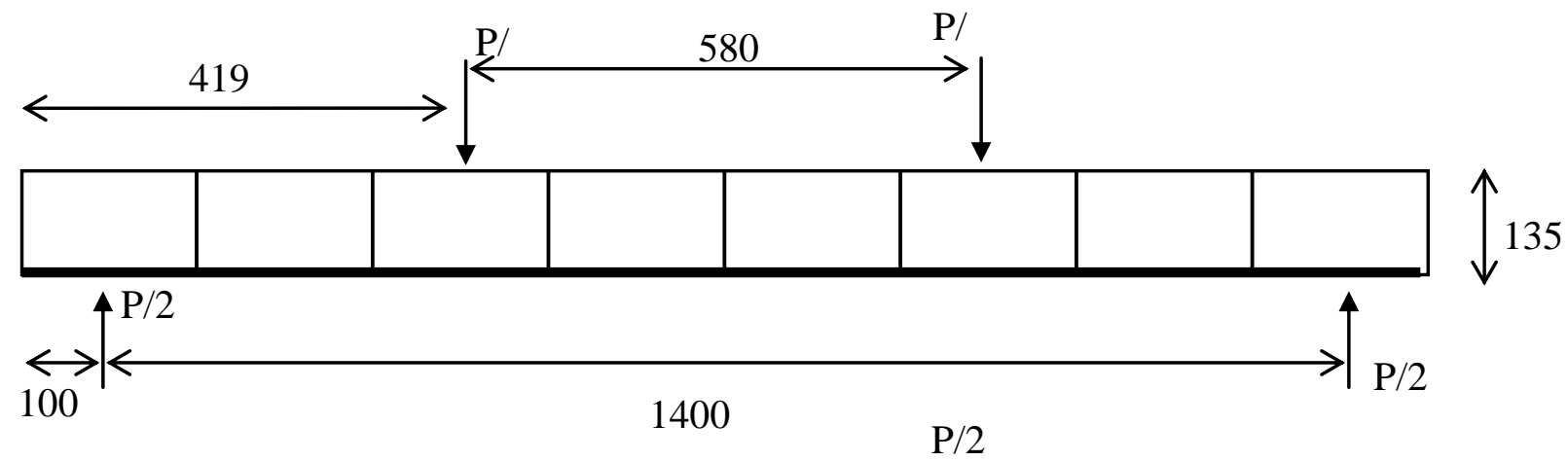

68

69

70

71

72

73

74

75

76
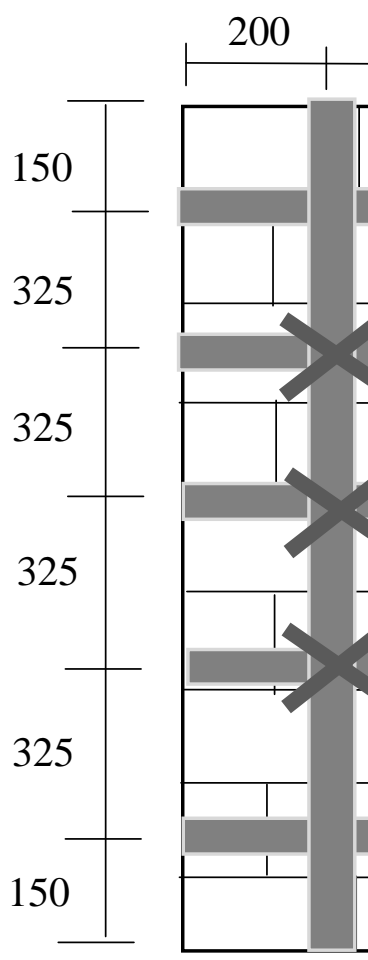

350 i-

200

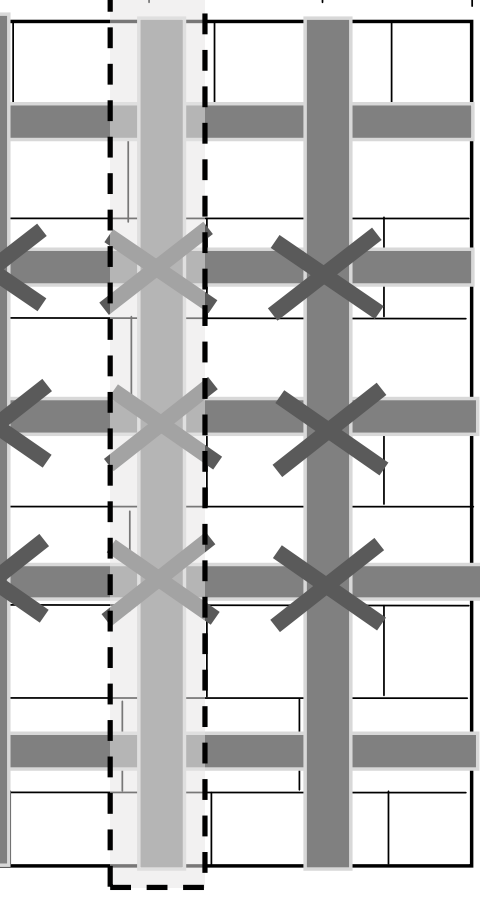

Speciment 11

$77 \quad$ a. Anil's test setup

78

79

80

81

82 


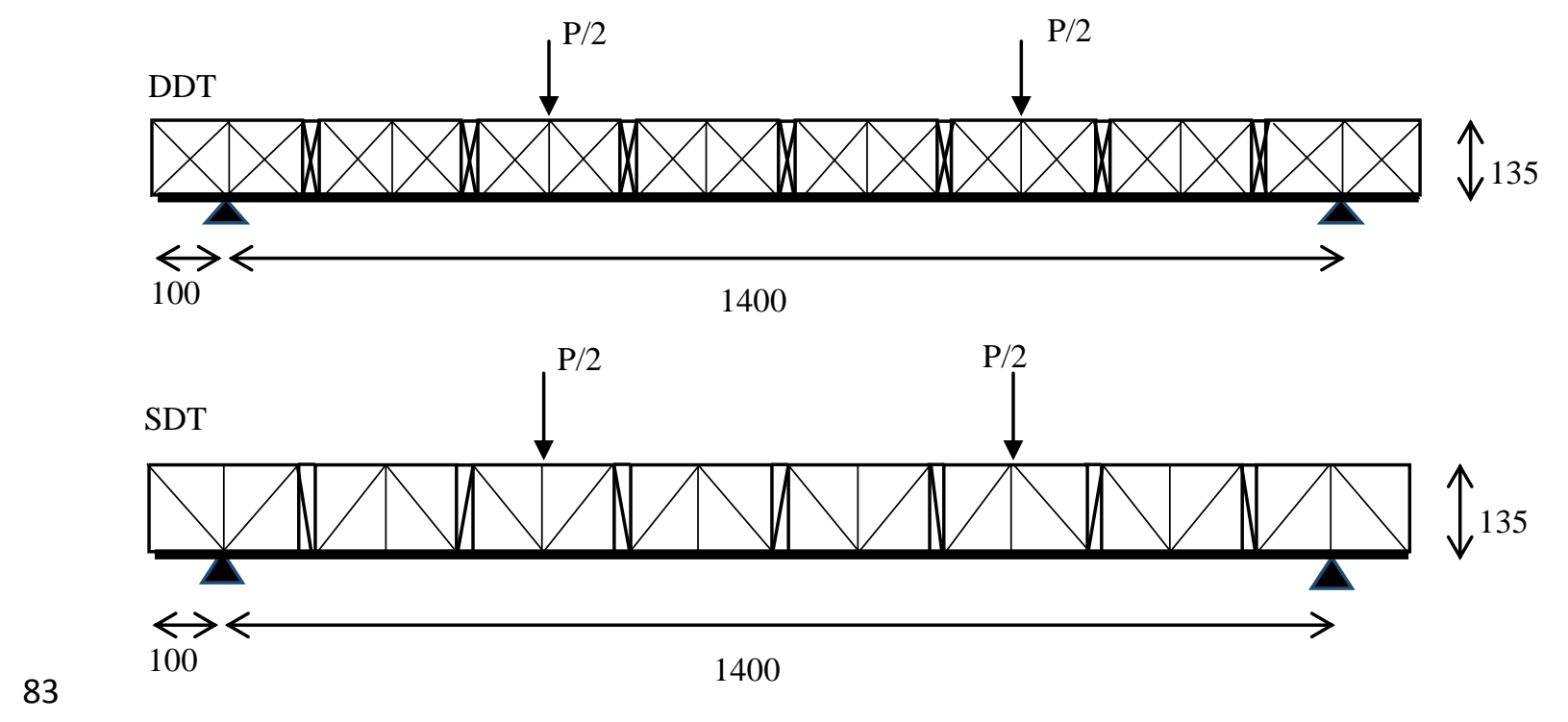

84

85
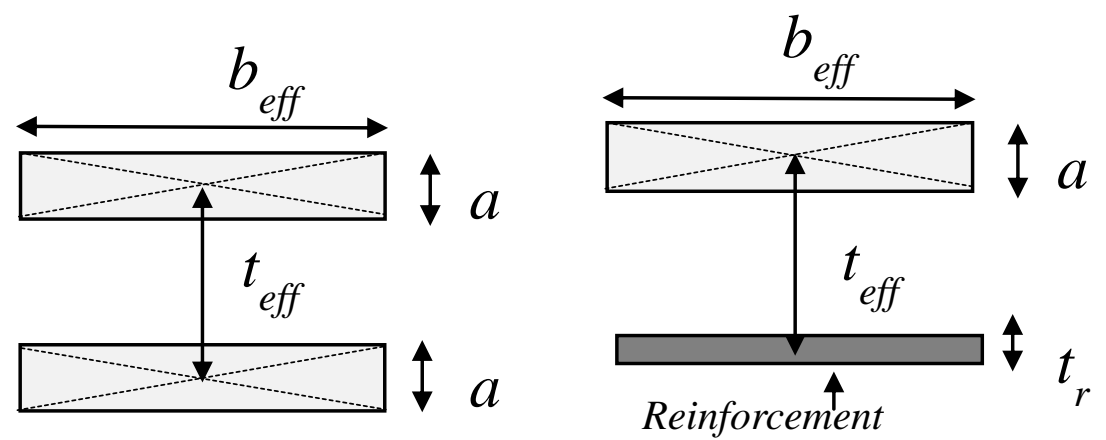

88

\begin{tabular}{ccccccc}
\hline$L(\mathrm{~mm})$ & $H(\mathrm{~mm})$ & $t(\mathrm{~mm})$ & $b_{\text {eff }}(\mathrm{mm})$ & $a(\mathrm{~mm})$ & $y(\mathrm{~mm})$ & $t_{\text {eff }}(\mathrm{mm})$ \\
& & & & & & \\
\hline 1100 & 1600 & 135 & 185 & 37.29 & 52.50 & 105.00
\end{tabular}

89

b. FTM model

90

Figure 12. Anil's test setup and FTM model.. 


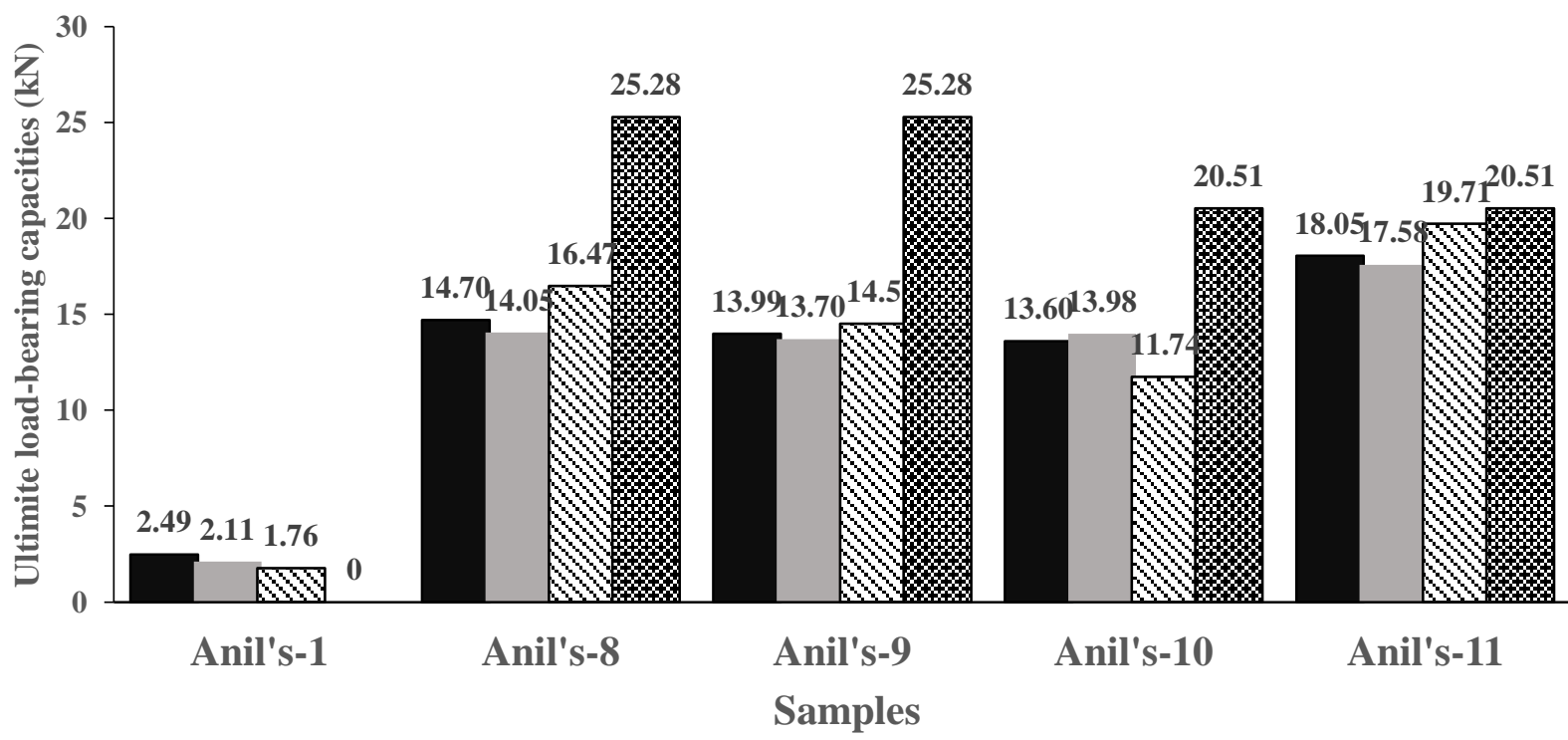

94

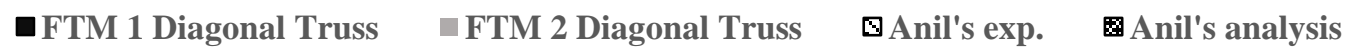

95 Figure 13. Comparison of results for the third validation experiment.

96

97

98

99

100 